\title{
The dynamics, processes, mechanisms, and functioning of personality: An overview of the field
}

\author{
Niclas Kuper ${ }^{\dagger *}$ (D), Nick Modersitzki $i^{\dagger *}$ (D), Le Vy Phan ${ }^{\dagger *}$ (D) and \\ John F. Rauthmann
}

Abteilung Psychologie, Universität Bielefeld, Germany

\begin{abstract}
Personality psychology has long focused on structural trait models, but it can also offer a rich understanding of the dynamics, processes, mechanisms, and functioning of individual differences or entire persons. The field of personality dynamics, which works towards such an understanding, has experienced a renaissance in the last two decades. This review article seeks to act as a primer of that field. It covers its historical roots, summarizes current research strands - along with their theoretical backbones and methodologies - in an accessible way, and sketches some considerations for the future. In doing so, we introduce relevant concepts, give an overview of different topics and phenomena subsumed under the broad umbrella term 'dynamics', and highlight the interdisciplinarity as well as applied relevance of the field. We hope this article can serve as a useful overview for scholars within and outside of personality psychology who are interested in the dynamic nature of human behaviour and experience.
\end{abstract}

Explaining individual differences in what people think, feel, and want, and how they behave is at the core of many psychologists' research and the central object of investigation of personality dynamics. Personality dynamics is an active research area in personality psychology that has seen a surge in empirical publications in the recent decade (Revelle \& Wilt, 2020). It concerns the investigation of intra-individual personality processes, mechanisms, and functioning, as well as inter-individual differences therein. Contrary to the descriptive study of trait structures, the study of personality dynamics aims to provide an explanatory account of an individual's thoughts, feelings, motivations, and behaviours and their patterning (Baumert et al., 2017; Cervone \& Little, 2019).

Despite the popularity of a more dynamic understanding of personality in the last years, the topics and research questions studied are anything but new. The conceptual foundation for personality dynamics has been discussed as early as in the 1870s by experimental psychologists in France (Lombardo \& Foschi, 2003). In 1930, Allport and Vernon published a detailed review about the field of personality dynamics up to this

This is an open access article under the terms of the Creative Commons Attribution License, which permits use, distribution and reproduction in any medium, provided the original work is properly cited.

*Correspondence should be addressed to Niclas Kuper, Nick Modersitzki, and Le Vy Phan, Abteilung Psychologie, Universität Bielefeld, Universitätsstraße 25, D-336I5 Bielefeld, Germany (emails: niclas.kuper@uni-bielefeld.de; nick.modersitzki@unibielefeld.de; le.phan@uni-bielefeld.de).

Shared authorship.

The first three authors share the (first) authorship and are also the corresponding authors. 
point. Moreover, the themes and research questions relevant to personality dynamics have been discussed by several eminent psychologists such as Freud (1958), Lewin (1951), Allport (1937), Kelly (1955), and Rogers (1959) - with varying degrees of scientific rigour and legitimacy. Importantly, interest in personality dynamics has been present throughout the existence of psychology as a science.

However, the empirical investigation of personality dynamics has long been hindered by both technological hurdles and a prevailing focus on individual differences taxonomies in the personality-psychological landscape since the 1960s (Cervone \& Little, 2019). With the rise of new technologies (e.g., enabling experience sampling studies or passive sensing; see Csikszentmihalyi \& Larson, 2014; Harari, Müller, Aung, \& Rentfrow, 2017; Wiernik et al., 2020) and statistical methods (e.g., multilevel modelling, network analysis, dynamic system models) that allow for the collection and analysis of (high-density) longitudinal data, the empirical study of personality dynamics has found a revival in interest (Cervone \& Little, 2019; Hamaker \& Wichers, 2017). Furthermore, current personality dynamics researchers can draw on the amassed knowledge of other relevant disciplines such as cognitive, experimental, social, and developmental psychology, or neuroscience, which are critical to understanding the causal systems underlying personality expressions (Cervone \& Little, 2019; Quirin et al., 2020). This makes contemporary personality dynamics a highly integrative and transdisciplinary science that informs both basic psychological research and domains of applied psychology.

The purpose of this paper is to introduce the field of personality dynamics into mainstream psychology, provide a primer for scholars interested in a more dynamic understanding of personality, and thereby facilitate the study of dynamics across disciplines. To this end, we provide a brief overview of the past, present, and future of the field. First, we highlight the relevance of the field and introduce central concepts to ensure conceptual clarity and consistency. We then briefly outline the history of the field and provide an overview of contemporarily dominant dynamic models and theories of personality. We next describe the principles of empirical research and briefly highlight the applied relevance of personality dynamics. We conclude with suggestions for future directions.

Given the broad scope of this article and its limited length, this work cannot represent a comprehensive review of the literature on personality dynamics. We focus more on the conceptual underpinnings of theoretical models and methodological approaches rather than on specific empirical findings. Further, we mainly refer to short- and middle-term dynamics since most of the research reviewed here deals with processes and mechanisms occurring in shorter time frames. Of course, we acknowledge the importance of long-term dynamics (e.g., personality development) and their study (Asendorpf, 2020; Wrzus, 2020). However, this research area can be included only very selectively in this article, and readers are referred to the extensive personality development literature instead (Bleidorn et al., 2020). For an extensive account of diverse perspectives on current research in personality dynamics, the reader is referred to the recently published Handbook of Personality Dynamics and Processes (Rauthmann, 2020b).

\section{Relevance of the field}

From a basic research perspective, the study of personality dynamics is important because it strives for an understanding of the causal principles that govern the ways humans navigate through life and seeks to explain how personality 'works'. Given this explanatory 
claim, the examination of processes, mechanisms, and functioning has to be inherent to the study of personality (Baumert et al., 2017). That is, to understand a person affords studying the dynamic patterning of their thoughts, feelings, motivations, and behaviours (Revelle \& Wilt, 2020). Personality psychology has been dominated by nomothetic perspectives (i.e., generalizing across individuals) in the past and neglected idiographic perspectives (i.e., individual-specific). One strength of the study of personality dynamics is that it combines nomothetic and idiographic approaches (Revelle \& Wilt, 2020). Due to its holistic and complex nature, the field of personality dynamics affords and enables interdisciplinary research and theory-building. Many existing theories, models, and frameworks in the field draw on knowledge from other psychological disciplines (see Contemporary theoretical dynamics-focused approaches in personality science). At the same time, insights gained from personality dynamics research can inform neighbouring disciplines that are concerned with individual differences or within-person variability in experiences and behaviour. Such insights are also relevant for applied psychology (see Personality dynamics in applied settings). By moving across disciplinary borders, personality dynamics research facilitates interdisciplinary (i.e., synthesized) or transdisciplinary (i.e., unified) perspectives on personality.

\section{Central concepts}

To increase conceptual clarity and consistency of terms used in personality dynamics research, we compiled a list of central terms, working definitions, and corresponding references (Table 1). Additionally, Figure 1 provides an illustration of the key terms 'dynamics', 'processes', 'mechanisms', and 'functioning'. We chose working definitions that are broad enough to be inclusive and applicable for most of the approaches discussed here. However, different authors may use these terms differently than they are defined in Table 1, and we decided not to alter their terminology when discussing their work in later sections (e.g., Table 2). The practice of using the same terms for different phenomena (jingle fallacy) and different terms for the same phenomena (jangle fallacy) is unfortunately widespread in personality dynamics research which impedes the integration of different lines of work. Furthermore, we modified some definitions with the goal of circumventing conceptual circularities (i.e., to distinguish between explananda - the phenomena to be explained - and explanantia - the phenomena explaining them; Uher, 2016, 2017). Of course, we do not claim that the definitions chosen here are allencompassing, commonly accepted, or represent the ground truth. Defining concepts in personality psychology is exceptionally difficult given the plurality of models and resulting jingle-jangle fallacies in the field as well as the origin of many terms in natural language (Cervone \& Little, 2019). Nevertheless, we believe that by providing explicit definitions, we can increase clear and consistent communication.

The first term that should be defined is personality dynamics itself. Personality dynamics is an umbrella term that encompasses all processes, mechanisms, and changes that are involved in the development and manifestation of personality (Figure 1). It includes normative dynamics (e.g., average contingencies between situation variables and states) and individual differences therein. Personality dynamics can be understood in a broad sense, covering dynamics in all psychological phenomena that show individual differences (i.e., most psychological phenomena). In a narrow sense, personality dynamics could be restricted to the study of dynamics in content domains represented in taxonomies of personality (e.g., Big Five / HEXACO traits and states, but also broader 
4 Niclas Kuper et al.

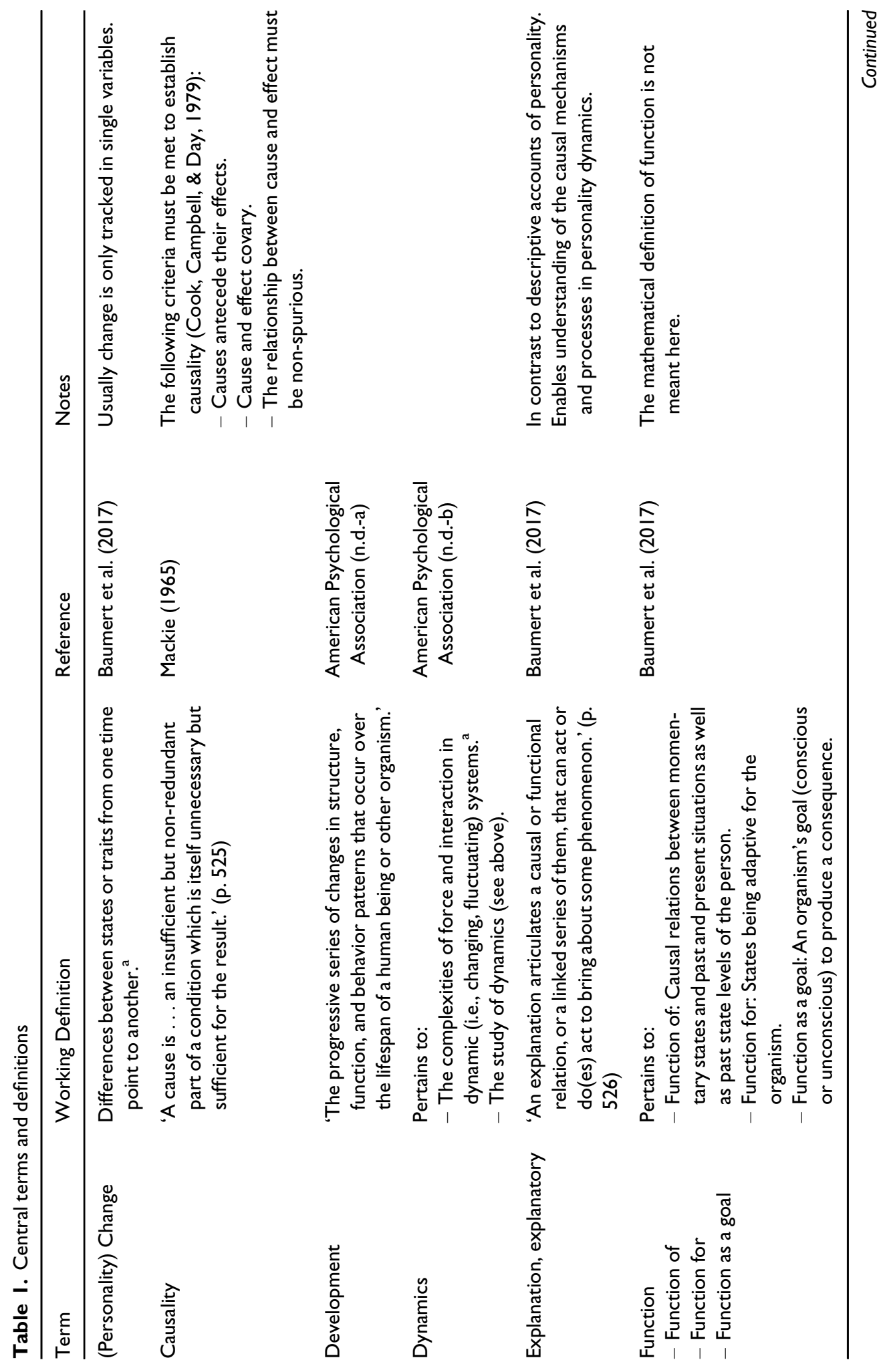




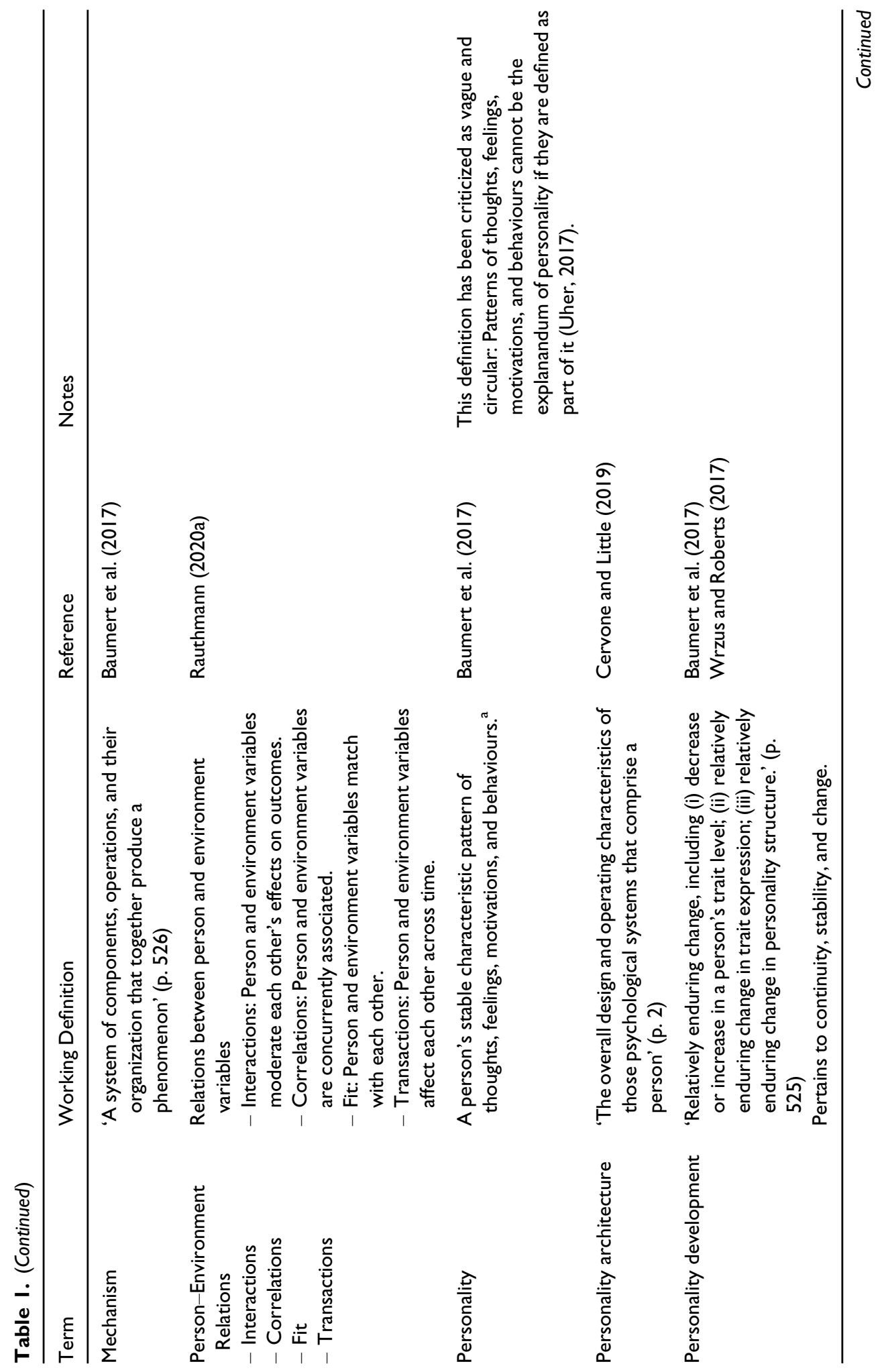




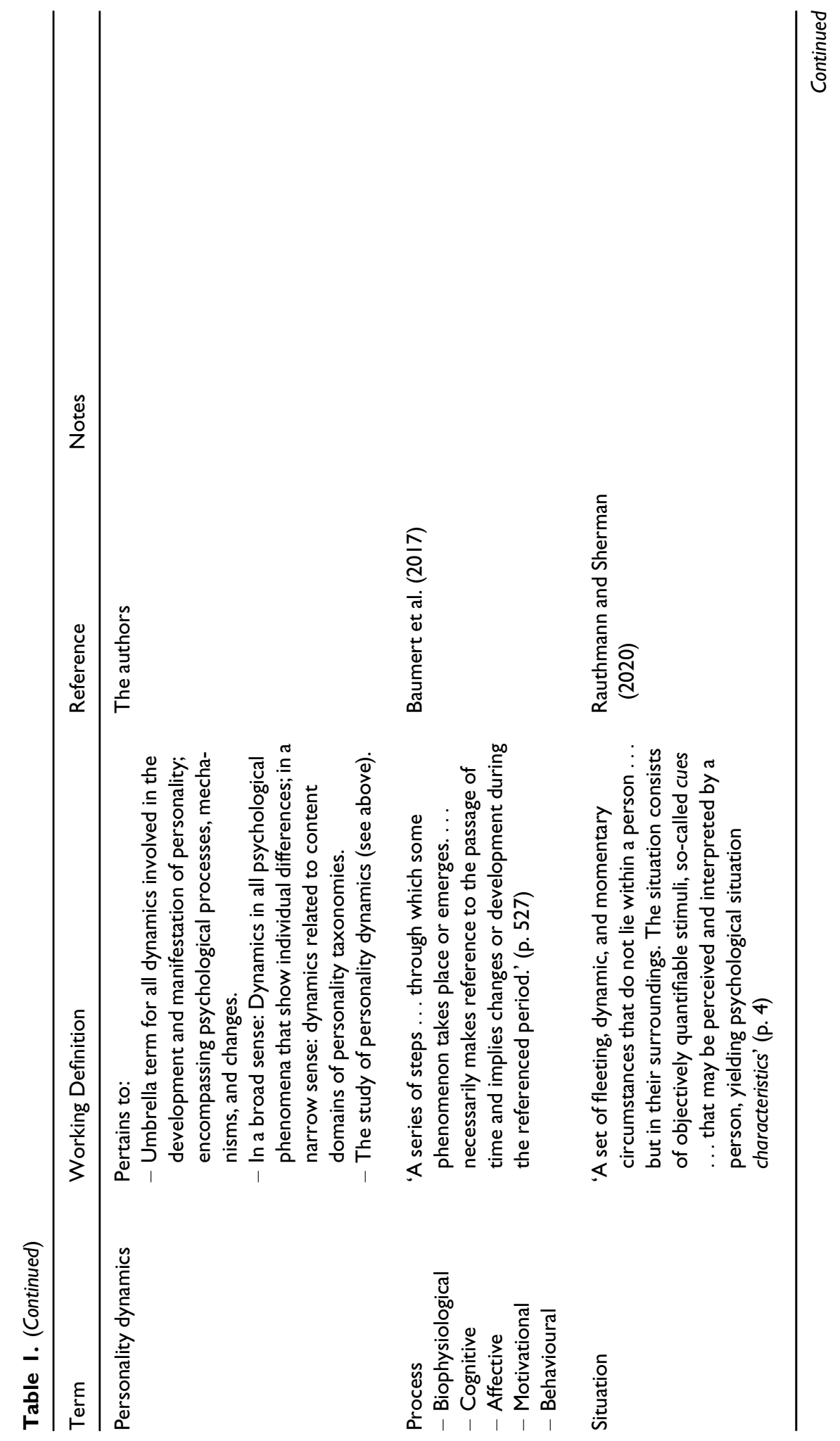




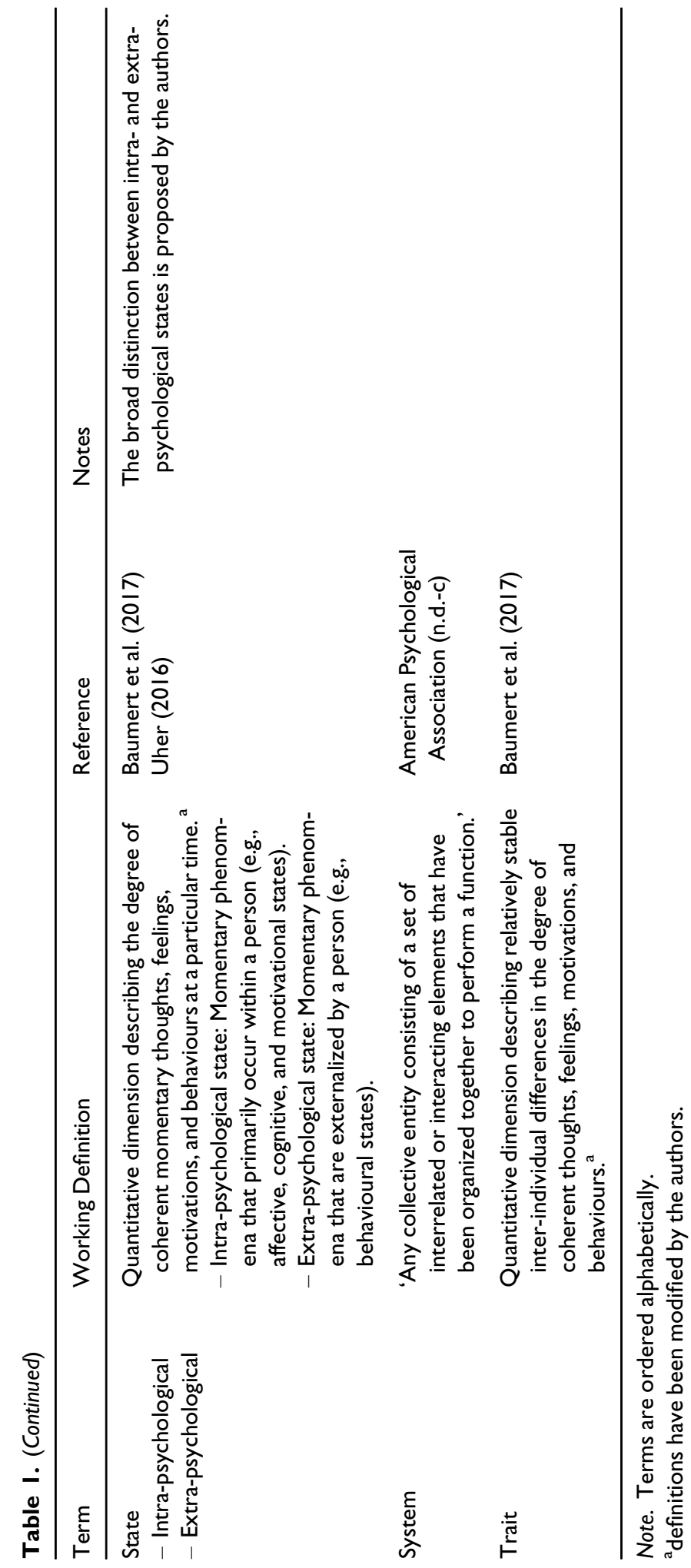




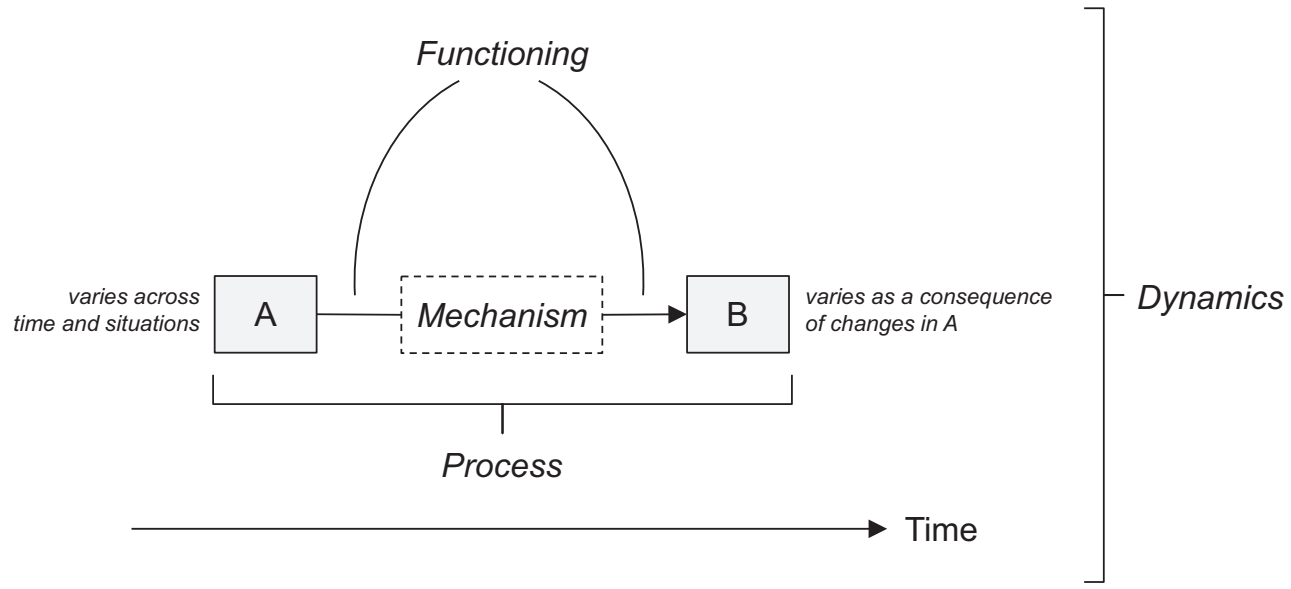

Figure I. Overview of Key Terms. Two focal variables, A and B, vary across time (and possibly also situations) and are thus changing. In this example, $B$ varies as a consequence of changes in $A$. B varies as a function of $A$ via an underlying mechanism (which can be another variable, process, or system). The sequence of $A$ to $B$ (via a mechanism) is a process. The concrete links of $A$ to $B$ (via a mechanism) across time describe the functioning of the variable system. Processes, mechanisms, and functioning can be subsumed under the umbrella term of dynamics.

conceptualizations, e.g., McAdams \& Pals, 2006). Personality dynamics is also the term used to describe the field dedicated to the study of personality processes, their causes, and outcomes. As the term already implies, the field examines dynamic phenomena (as opposed to static phenomena such as trait structures). Dynamics-focused theories can be viewed in a narrow sense where time is considered and modelled explicitly (e.g., Read et al., 2010; Revelle \& Condon, 2015) or in a broad sense where time-dependent processes are at least implied (e.g., Fleeson \& Jayawickreme, 2015).

As the passage of time is either explicitly or implicitly important, three other concepts are central: change, development, and situations. First, change and development always require a passage of time. Changes represent differences in a variable from one time point to the other, and development represents a series of changes across time. Second, time passing also means that situations vary. Personality dynamics do not occur in a vacuum but in specific situations. Situations are defined as momentary circumstances outside the person (i.e., in a person's surroundings) that are also inherently dynamic (Table 1). They contain objectively quantifiable stimuli that can be subjectively perceived and interpreted by persons to yield a psychological situation (Rauthmann, Sherman, \& Funder, 2015). The relations between person variables (i.e., states and traits), environment variables (i.e., momentary situations and stable niches), and relevant outcomes are subsumed under the term person-environment relations. Person-environment relations encompass interactions, correlations, fits, and transactions (Rauthmann, 2020a).

In personality dynamics, mechanisms and processes are central objects of investigation. Mechanisms are systems of components and operations that are organized to produce certain phenomena (Table 1). The mechanistic view is adopted from physics and is concerned with the function ('why?') and causality ('how?') of psychological phenomena (Casadevall \& Fang, 2009). Mechanisms can be processes, but unlike processes, they do not have to precede the phenomenon they produce (Baumert et al., 


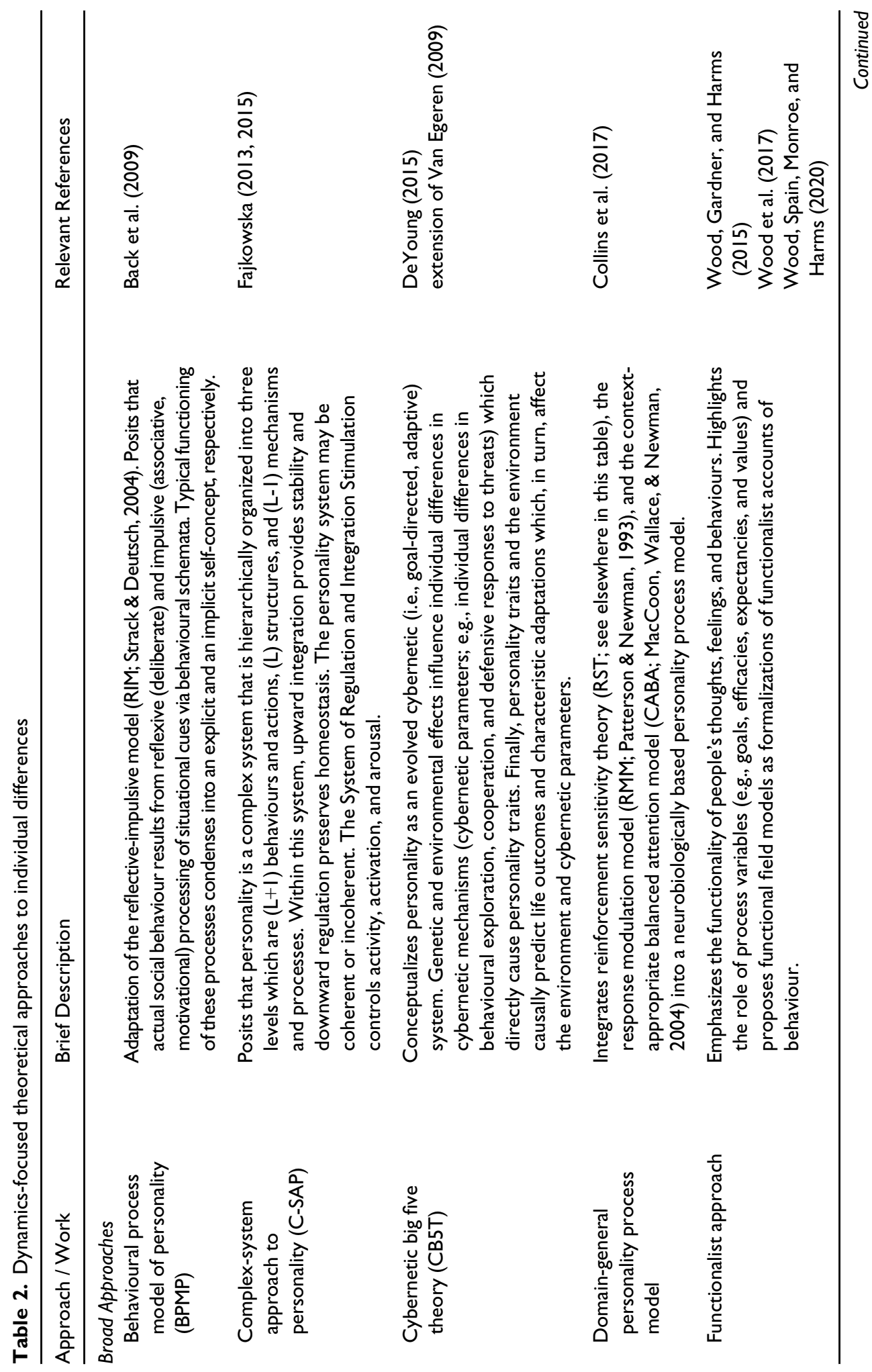




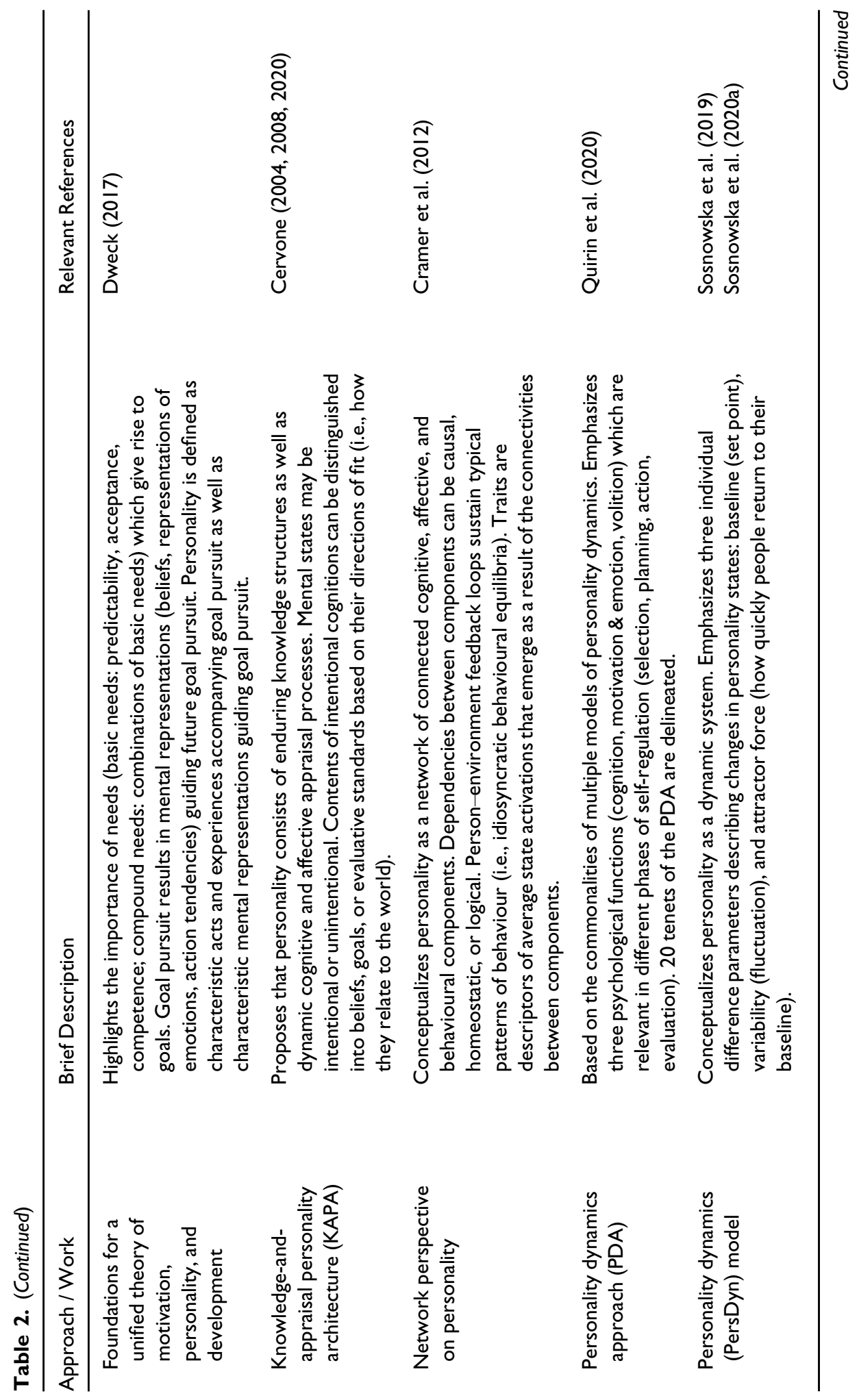




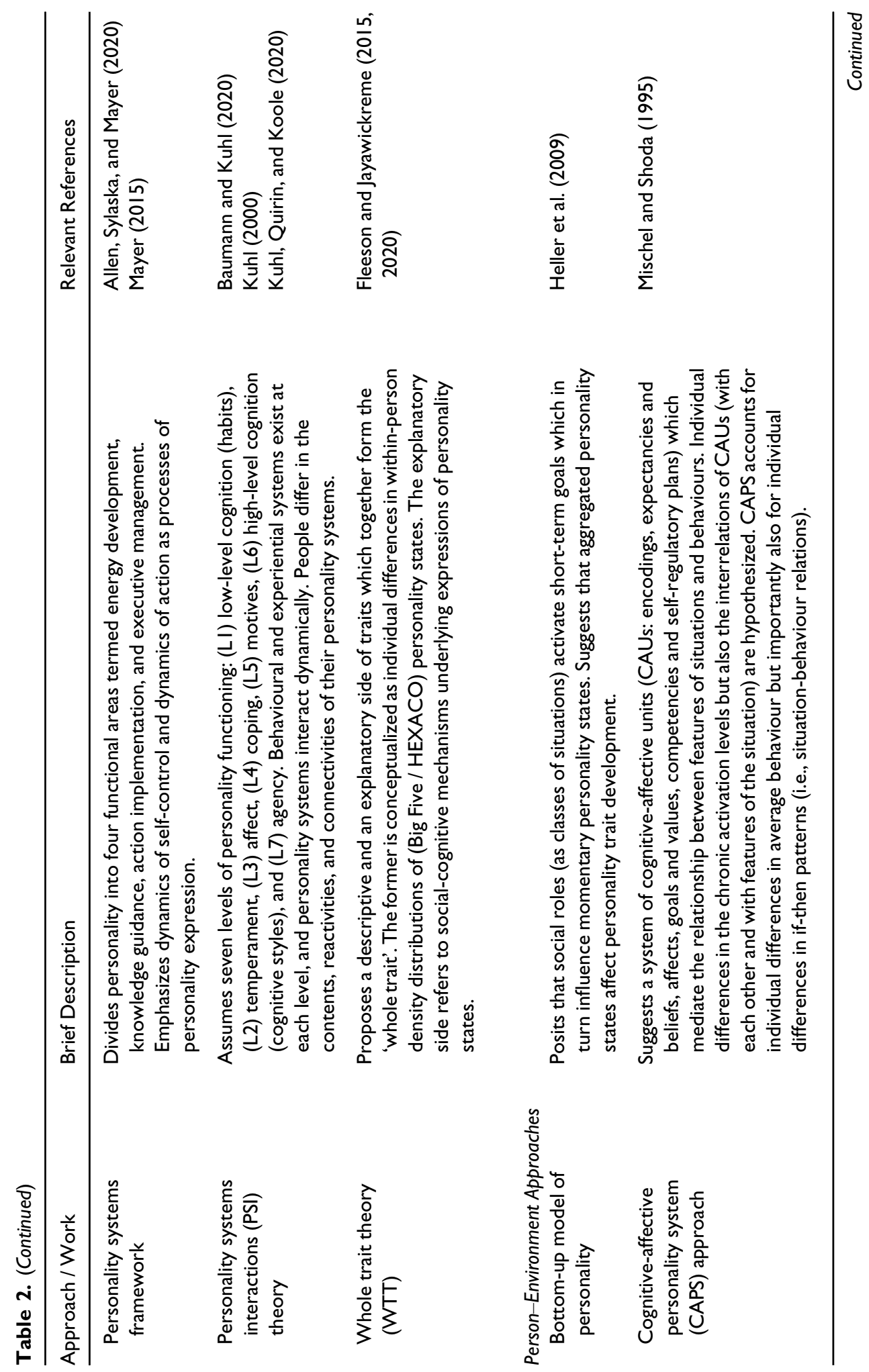




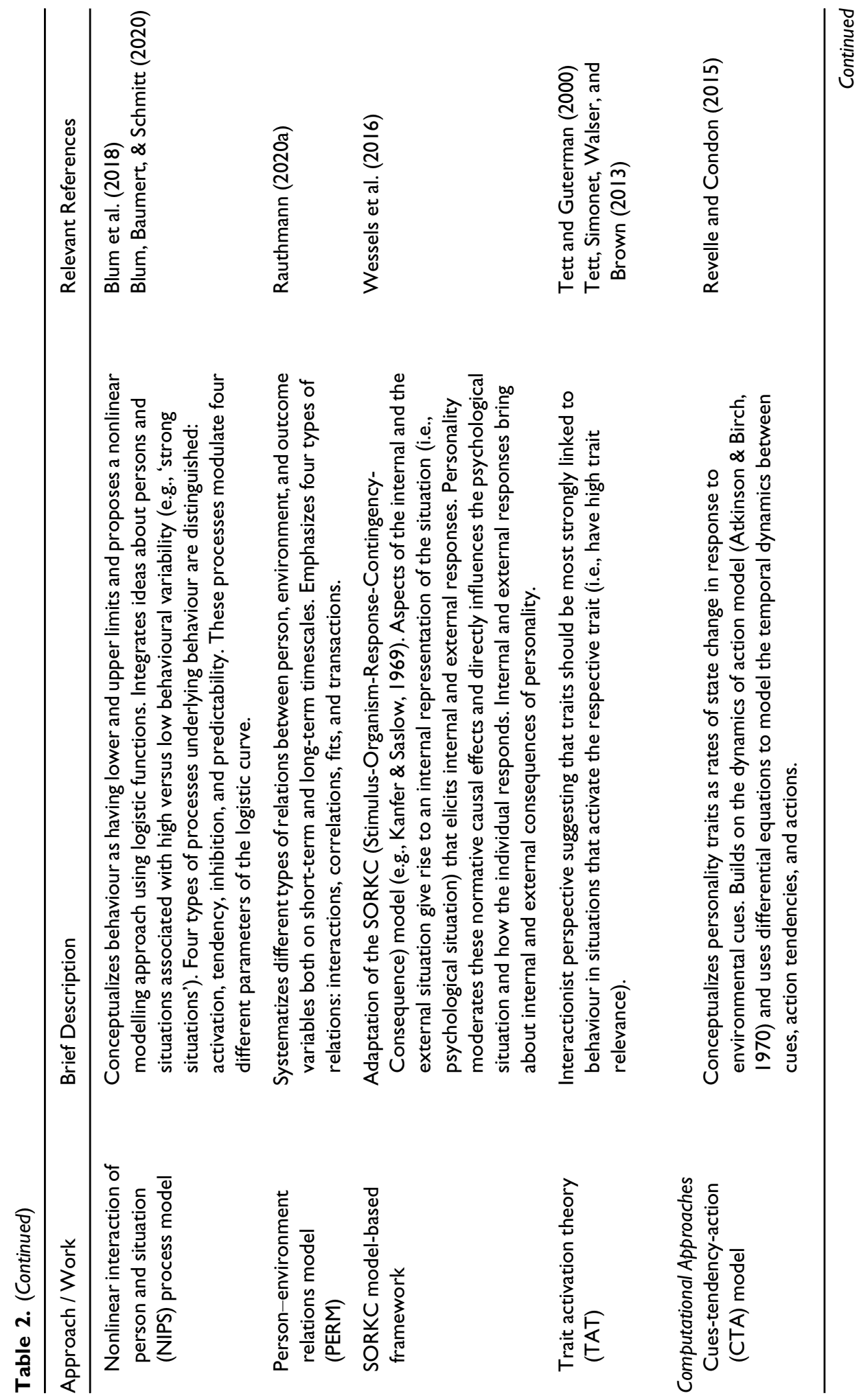




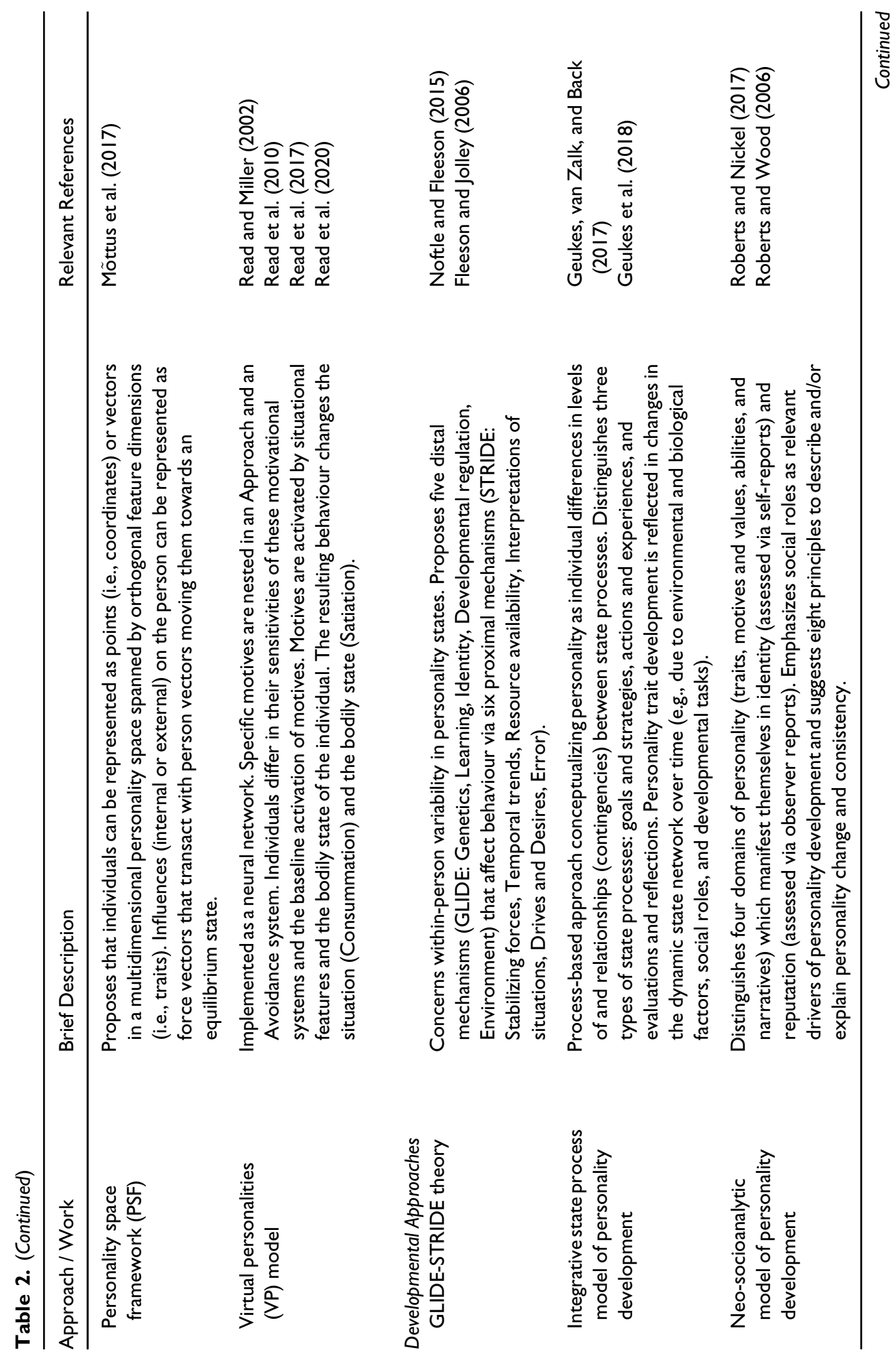




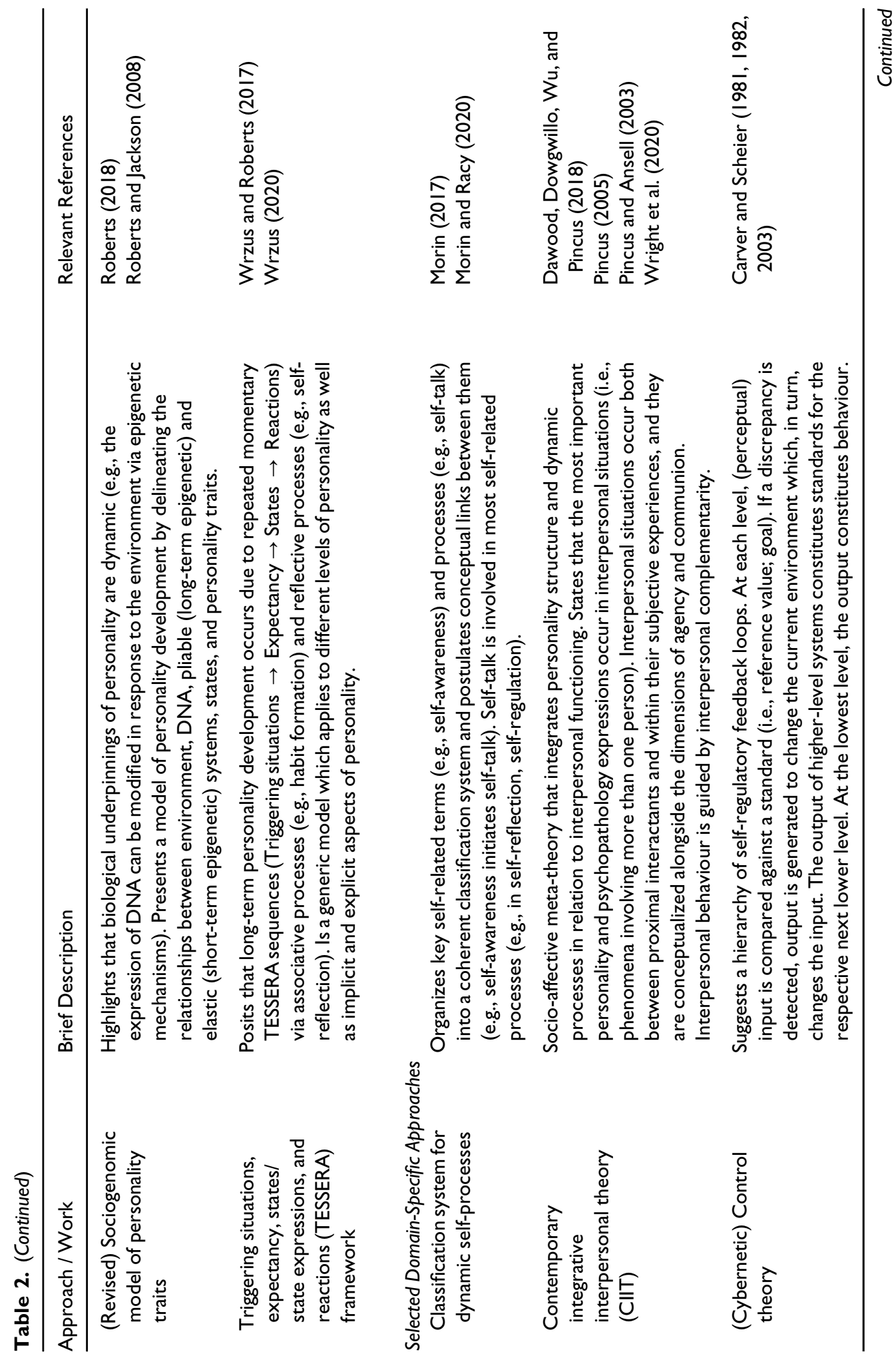



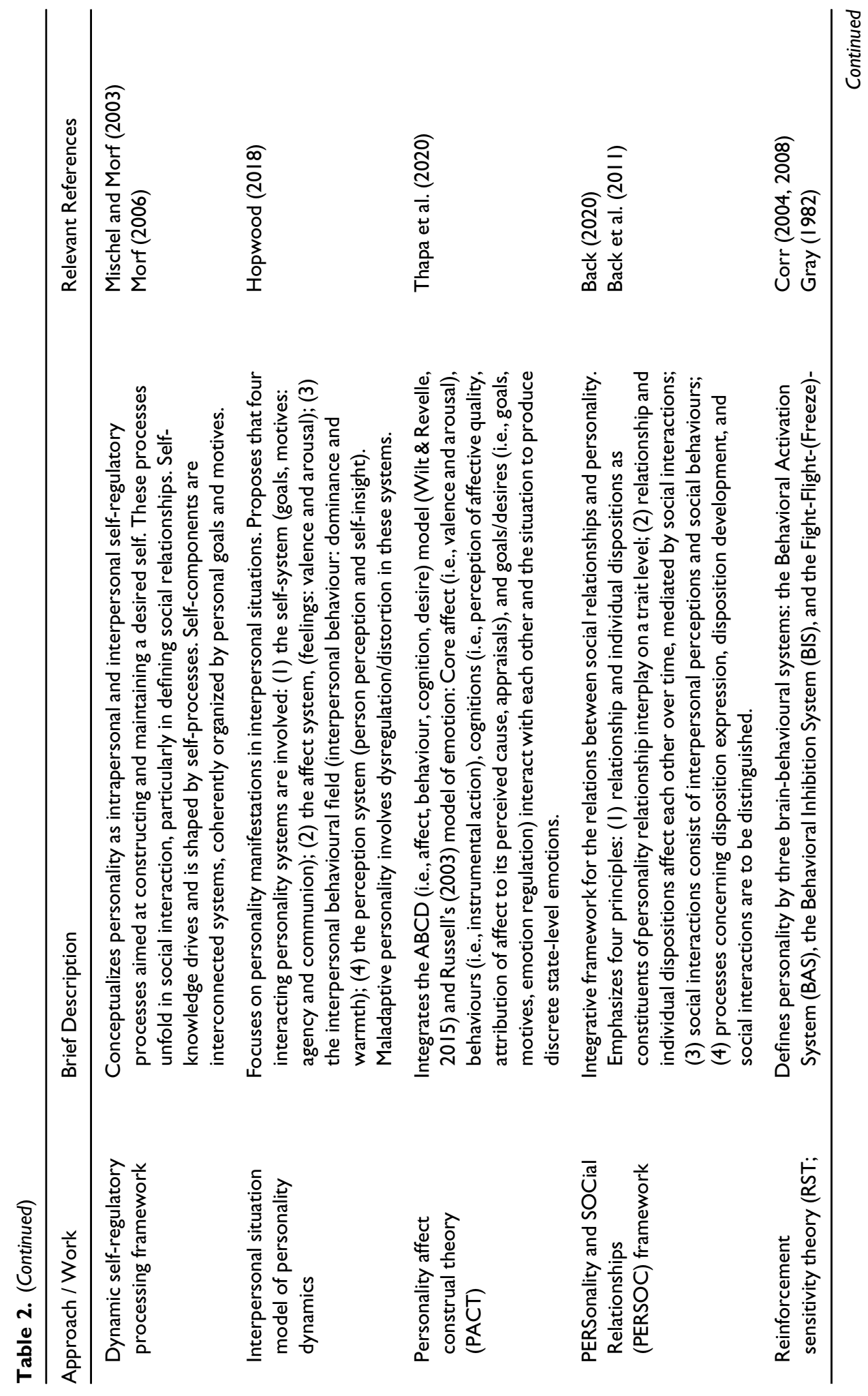

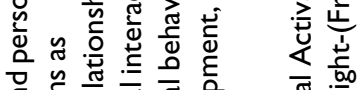
氜

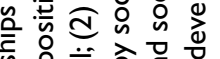

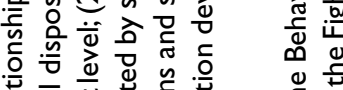

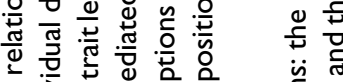

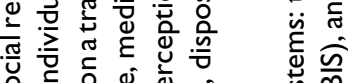

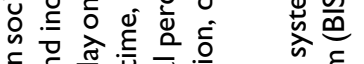

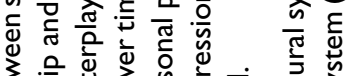

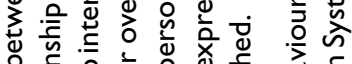

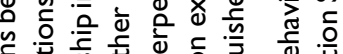

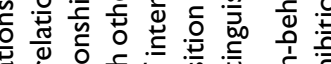

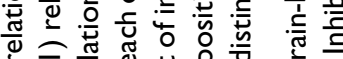

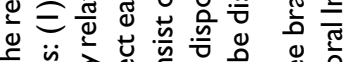

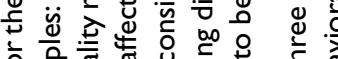
妾

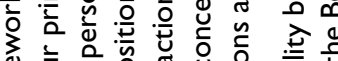

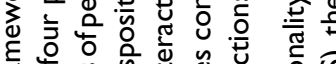

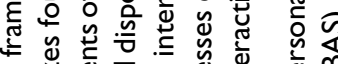

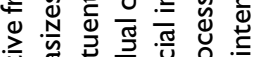

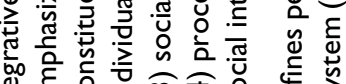

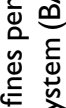
总
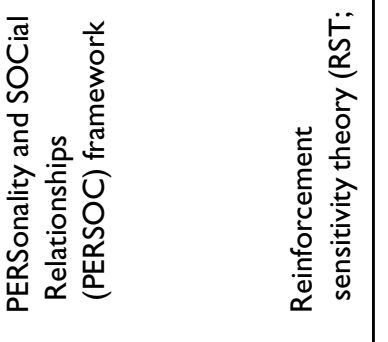


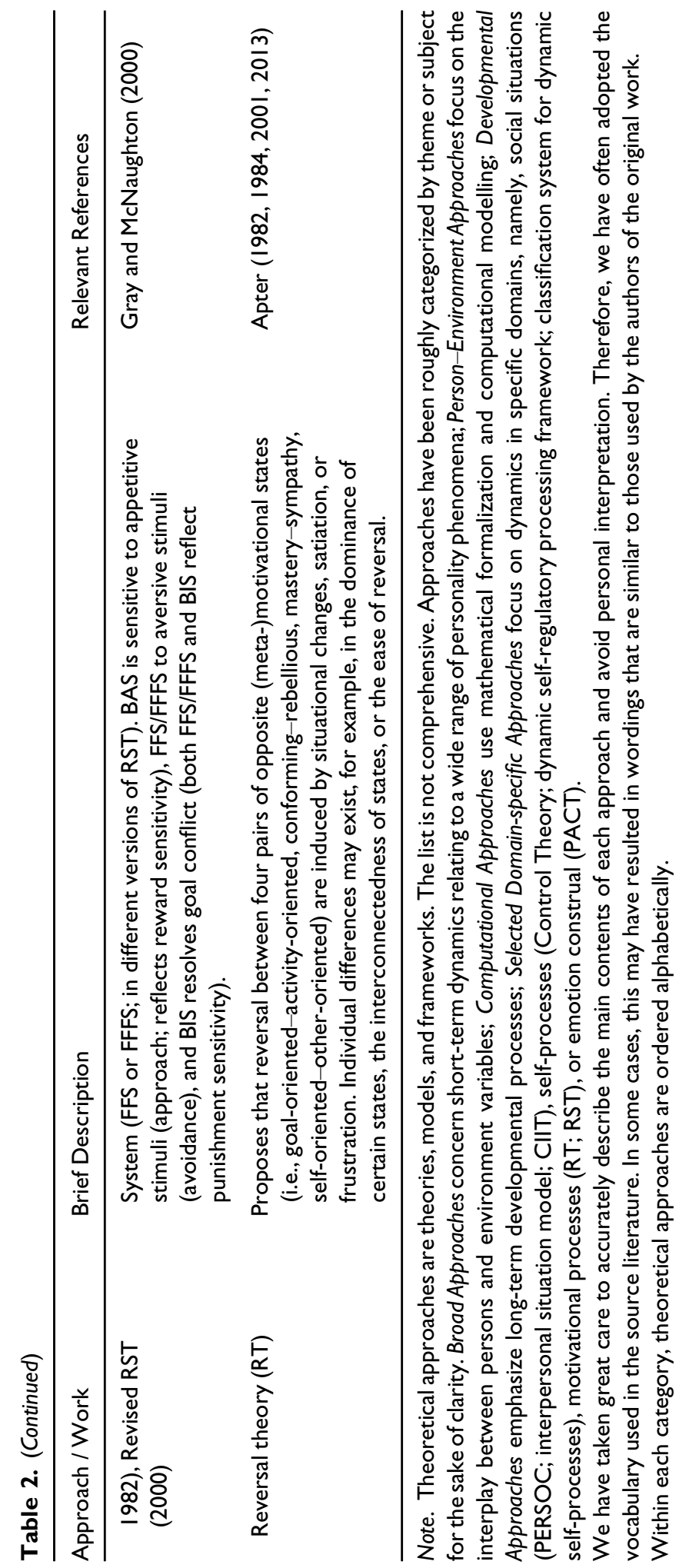


2017). Processes refer to series of steps through which a phenomenon takes place and thus imply the passage of time (Table 1). Processes are, therefore, inherently dynamic. Processes are central to personality dynamics because they have the potential to explain inter- and intra-individual differences in personality expressions. Processes can be biophysiological, cognitive, affective, motivational, or behavioural and can co-occur sequentially or in parallel (e.g., DeYoung, 2015; Quirin et al., 2020). Biophysiological processes include processes pertaining to brain function (e.g., action potentials, brain waves, neurotransmitter activity) and the body in general (e.g., heart rate, skin conductance, pupil dilation). Cognitive processes are involved in all forms of information processing and the processing of sensory input (Neisser, 1967) and can include sensory, perceptual, and regulatory processes. Affective processes are involved in subjective experiences of pleasure/displeasure and activation (Baumert et al., 2017). Motivational processes are involved in the selective approach/avoidance of certain situations or features thereof (Baumert et al., 2017). Lastly, behavioural processes are motoric and usually externalized by a person; that is, they occur outside the body of a person (Uher, 2016).

Personality processes may constitute or result in momentary thoughts, feelings, motivations, and behaviours that are manifested by a person and are referred to as states. States can be associated with traits, other concurrent and past states, and the current and preceding situation. We further draw the distinction between intra-psychological and extra-psychological states to distinguish internal momentary phenomena that primarily occur within a person (e.g., cognitive, affective, and motivational states) from momentary phenomena that are mostly externalized (e.g., behavioural states). ${ }^{1}$ In the field of personality dynamics, personality states - often treated as the units that are dynamic or that underlie more static units ${ }^{2}$ - are a fundamental concept. These can be differentiated from psychological states in general as they are intimately linked to personality traits (Horstmann \& Ziegler, 2020). However, personality states are defined differently in the literature. According to Fleeson (2007), personality states are dimensions with the same scale and content as their corresponding personality traits but refer to how a person is at the moment. Others view personality states as states that are indicative for personality traits (Horstmann \& Ziegler, 2020) and argue that personality states must serve a specific trait-congruent function (Schmitt, 2009). This means that although the content of a state (e.g., being talkative) might match a specific personality trait in terms of content (e.g., extraversion), it is not indicative of this trait - and hence not a state expression of the traitif its function corresponds to another trait (e.g., conscientiousness due to a networking situation at work).

As alluded to in the example above, another common theme of dynamic personality models is functions or functioning of processes. Function can pertain to three meanings here (Baumert et al., 2017). First, functionalistic dynamic approaches (e.g., Wood, Spain, \& Harms, 2017) assume that a person's individual patterning of thoughts, feelings, and behaviours is influenced by a person's goals, values, motives, or interests. Second, function is also used to describe the causal relations of a momentary state to past states or

\footnotetext{
${ }^{\prime}$ Additionally, there can also be intra-biophysiological states (e.g., heartbeat) and extra-biophysiological states (e.g., pupil dilation, transpiration).

${ }^{2}$ Personality states are usually conceptualized as reflective manifestations of corresponding personality traits (e.g., Baumert et al., 2017; DeYoung, 2015; Fleeson \& Jayawickreme, 2015; Funder, 200I; Horstmann \& Ziegler, 2020, Wrzus \& Mehl, 20I5). However, some researchers assume a formative trait conceptualization (i.e., that states make up the trait; e.g., Buss \& Craik, 1983; Cramer et al., 2012).
} 
past and present situations. Lastly, a state can be functional for a person if that state is adaptive (i.e., serving a certain purpose).

Finally, several dynamic theories of personality assume and examine underlying personality systems. Systems are collective entities of interrelated elements that together perform a function. Indeed, personality itself is often conceptualized as a complex system (e.g., DeYoung, 2015; Kuhl, 2000; Mayer, 2015; Mischel \& Shoda, 1995).

The terms introduced in this section emerged from a long line of research on personality dynamics and are as central to personality science today as they have been in the past. In the next section, we provide a selective overview of historical accounts before we delve into current theoretical and empirical work on personality dynamics.

\section{A (very brief) history of personality dynamics}

In this section, we briefly review three selected dynamic accounts that have been historically influential. For excellent and more comprehensive historical overviews, we refer to Revelle and Wilt (2020) and Cervone and Little (2019). As mentioned earlier, personality dynamics research has been around for as long as the field of scientific psychology itself. Allport, one of the founding fathers of personality psychology, emphasized personality dynamics throughout his career. In his view, personality is 'the dynamic organization within the individual of those psychophysical systems that determine his unique adjustments to his environment' (Allport, 1937, p.48). He stressed processes and functioning within a person (Allport, 1937) and highlighted the importance of idiographic approaches and how nomothetic and idiographic perspectives complement one another (Allport, 1968).

In 1946, Cattell introduced his 'covariation chart' which depicts the organization of data on three axes: persons, variables, and occasions. Much personality-psychological research examined correlations of variables across persons at one time point (but also correlations of persons across variables to identify types with similar profiles). Including a temporal dimension (i.e., occasions) allowed for a dynamic approach where variables could be examined within persons (or a single person) across multiple occasions. This laid the foundation for the analysis of longitudinal data and research concerning continuity, stability, and change (e.g., Caspi, Roberts, \& Shiner, 2005; Roberts \& DelVecchio, 2000; Roberts, Walton, \& Viechtbauer, 2006).

Perhaps the most influential among historical dynamic approaches has been Kurt Lewin's field theory $(1936,1951)$. In his famous equation $\mathrm{B}=f(\mathrm{P}, \mathrm{E})$, Lewin expressed behaviour as a function of a person's momentary mental states and the momentary environment. Lewin viewed the person and environment states as interdependent, and he highlighted the dynamic nature of behaviour and its changes over time and space. Furthermore, he emphasized the importance of integrating idiographic and nomothetic approaches (Lewin, 1935). Field theory draws on topological principles and posits a 'life space' representing all intra- and extra-psychological and environmental factors influencing a person's behaviour at any given time. Lewin's focus on the whole situation, a person's goals, and on causal explanations of a person's behaviour has been visionary, and modern personality dynamics research can still build on his ideas.

The approaches mentioned above - but also other historical approaches emphasizing, for example, constructivist idiographic perspectives (e.g., Kelly, 1955), motivation in the context of dynamics (e.g., Atkinson \& Birch, 1970), or the capacity for personality development (i.e., persons as agentic operators interacting with their environment; e.g., 
Bandura, 1986, 1999; McAdams, 2013; Rogers, 1959) - form the basis for more recent work on personality dynamics. An overview of current dynamic conceptualizations of personality is given in the next section.

\section{Contemporary theoretical dynamics-focused approaches in personality science}

To truly advance our understanding of personality dynamics, it will be necessary to zoom in on processes (Baumert et al., 2017; Quirin et al., 2020). To this end, various dynamicsfocused theoretical approaches have been proposed. For a selective overview of contemporary approaches, see Table 2 . We use 'theoretical approaches' as an umbrella term to encompass theories, models, and frameworks. Most approaches listed in Table 2 are contemporary in that they have been proposed in the last two decades, although we also included selected earlier approaches that have remained influential in the field. These approaches have in common that they emphasize the role of processes and mechanisms underlying inter-individual and intra-individual variability rather than being restricted to describing trait structures. Several prominent approaches attempt to integrate personality dynamics and structure. Whole trait theory (WTT; Fleeson \& Jayawickreme, 2015, 2020), for example, posits that individual differences in Big Five personality traits can be understood as between-person differences in density distributions of personality states and proposes explanatory social-cognitive mechanisms underlying trait manifestations. As another example, cybernetic big five theory (CB5T; DeYoung, 2015) links individual differences in the Big Five traits to different cybernetic parameters.

While theoretical approaches emphasize the role of explanatory processes, they differ with respect to the specificity of the proposed processes. For example, WTT and the cognitive-affective personality systems (CAPS) model include relatively broad sets of social-cognitive processes (e.g., goals, self-regulatory plans, situation interpretations; Fleeson \& Jayawickreme, 2015; Mischel \& Shoda, 1995), while reinforcement sensitivity theory arguably proposes more specific processes such as punishment sensitivity (Corr, 2008; Gray \& McNaughton, 2000). Some more trait-specific models not included in the table postulate even more specific processes (e.g., perception of status gain or loss in narcissism dynamics: Back, 2018; Grapsas, Brummelman, Back, \& Denissen, 2020).

Several common themes of the theoretical approaches can be identified. First, many approaches explicitly emphasize cybernetic concepts such as goal-directedness, feedback processes, and (self-)regulatory aspects (e.g., Carver \& Scheier, 1981; DeYoung, 2015; Dweck, 2017; Fajkowska, 2015; Kuhl, 2000; Mischel \& Shoda, 1995; Morf, 2006; Quirin et al., 2020; Revelle \& Condon, 2015; Wood et al., 2017), although not all of these classify themselves as 'cybernetic approaches'. For example, cybernetic big five theory links traits to individual differences in cybernetic functions (e.g., extraversion to behavioural exploration; openness to cognitive exploration; agreeableness to cooperation; DeYoung, 2015).

Second, several approaches include concepts related to a 'dynamic self' (Markus \& Wurf, 1987), such as the implicit and explicit self-concept (Back, Schmukle, \& Egloff, 2009), self-regulation (e.g., Carver \& Scheier, 1981; Fajkowska, 2015; Kuhl, 2000; Morf, 2006; Quirin et al., 2020; similar concepts are covered in additional approaches in Table 2), and other self-processes (Morin, 2017). In addition to the self-related approaches included in Table 2, narrative identity (e.g., Adler, 2012; Dunlop, 2017; Lilgendahl \& McLean, 2019; McAdams \& McLean, 2013; McLean, Pasupathi, \& Pals, 2007; Pals, 2006), 
which concerns a person's internalized life story and its development, constitutes another approach worth noting. However, the self, identity, and personality literatures appear to be operating mostly in parallel with only occasional cross-cuttings. Further, apart from the specific and more circumscribed approaches referenced above, there does not seem to be any coherent model or framework of dynamic self-processes that underlie personality as a whole.

Third, multiple approaches highlight the importance of environmental variables such as situations for the understanding of dynamics (e.g., Blum et al., 2018; Heller, Perunovic, \& Reichman, 2009; Mischel \& Shoda, 1995; Rauthmann, 2020a; Tett \& Guterman, 2000; Wessels, Zimmermann, \& Leising, 2016). For instance, Rauthmann (2020a) has systematized four types of person-environment relations (correlations, interactions, fits, transactions), and studying them has been facilitated by recent empirical and conceptual advances in the area of psychological situation research (e.g., Rauthmann, Horstmann, \& Sherman, 2020; Rauthmann \& Sherman, 2020).

Fourth, a large number of theoretical approaches focus on long-term dynamics pertaining to personality development (e.g., Geukes, van Zalk, \& Back, 2018; Noftle \& Fleeson, 2015; Roberts, 2018; Roberts \& Nickel, 2017; Wrzus \& Roberts, 2017). As an example, the TESSERA framework posits that repeated momentary sequences (Triggering situations $\rightarrow$ Expectancy $\rightarrow$ States $\rightarrow$ Reactions) affect personality development through associative and reflective processes, such as habit formation and self-reflection (Wrzus \& Roberts, 2017).

Fifth, another important family of models are computational approaches which can be implemented as mathematical models in computer simulations (e.g., Mõttus, Allerhand, \& Johnson, 2017; Read et al., 2010; Revelle \& Condon, 2015). Importantly, given their high degree of formalization, these approaches allow for specific predictions that could be tested with empirical data (e.g., Read, Smith, Droutman, \& Miller, 2017, see also Robinaugh, Haslbeck, Ryan, Fried, \& Waldorp, 2020).

Finally, Table 2 includes selected approaches that focus on personality dynamics in specific domains (i.e., social situations: Back et al., 2011; Hopwood, 2018; Pincus, 2005; Wright, Pincus, \& Hopwood, 2020; self-processes: Carver \& Scheier, 1981; Morf, 2006; Morin, 2017; motivational processes: Apter, 1982; Gray \& McNaughton, 2000; emotion construal: Thapa, Beck, \& Tay, 2020).

Importantly, many of the intra- and interpersonal processes that are of interest to personality dynamics researchers are also studied in other psychological disciplines (e.g., cognitive, experimental, biological, social, developmental, clinical, work, and organizational psychology). Thus, personality dynamics may build on research from different areas such as social cognition (e.g., Back et al., 2009; Cervone, 2004; Fleeson \& Jayawickreme, 2015; Mischel \& Shoda, 1995), interpersonal theory (Hopwood, 2018; Pincus, 2005), or biopsychology and neuroscience (e.g., Collins, Jackson, Walker, O'Connor, \& Gardiner, 2017; DeYoung, 2015; Gray \& McNaughton, 2000; Read et al., 2010; Roberts, 2018).

In sum, multiple relevant theoretical approaches for the study of personality dynamics have been proposed. Many of these are complementary and can to some degree be integrated (e.g., Quirin et al., 2020), but they still each emphasize different aspects, serve different purposes, and sometimes use different terminology. Next, we will delve into superordinate principles of empirical research in personality dynamics which allow the examination of propositions derived from these theoretical approaches. 


\section{Principles of empirical research on personality dynamics}

As the field of personality dynamics is inherently concerned with changing rather than static phenomena, empirical research typically uses longitudinal (i.e., multi-occasion) data. Importantly, multi-occasion data can be used to examine processes (e.g., reinforcement learning) or other dynamic phenomena without drawing conclusions about the processes involved (e.g., intra-individual state variability). However, processes may also be inferred from their end products on the basis of single-occasion data (e.g., in laboratory experiments manipulating a process of interest once). In this overview, we will focus largely, but not exclusively, on multi-occasion studies given their suitability to more directly capture dynamic phenomena. A variety of viable study types and data sources exists, and they often make use of recent technological and methodological advances. When conducting dynamics-focused studies, it is vital to pay attention to measurement issues (e.g., psychometric properties of state measures) and appropriate sampling procedures (i.e., sampling of persons, situations, and state variables). Finally, various statistical approaches have been utilized or specifically developed for the analysis of dynamic data. In the following, we give a brief overview of these different methodological aspects and illustrate them with concrete empirical studies.

\section{Study types}

For an excellent overview of different study types suitable to capture personality processes, see Wrzus and Mehl (2015). Such studies can be distinguished along at least three dimensions: (1) context (laboratory vs. field), (2) design (observational vs. quasiexperimental vs. experimental), and (3) duration (e.g., single-occasion vs. several days, weeks, or years of measurements). Different realizations of these dimensions can be combined and yield various study types, some of which are more frequently used than others. Moreover, even studies with different realizations regarding the same dimension can be combined in a larger research project and may in fact facilitate more generalizable conclusions about dynamic phenomena (e.g., investigating reactivity to situational stimuli with the same participants in both experimental laboratory settings and in everyday life using experience sampling). In the following, we go into detail about three broad classes of frequently used study types: (1) ambulatory assessment, (2) laboratory studies, and (3) long-term panel studies.

Ambulatory assessment (Conner \& Mehl, 2015; Fahrenberg, Myrtek, Pawlik, \& Perrez, 2007; Wright \& Zimmermann, 2019), also referred to as ecological momentary assessment (Shiffman, Stone, \& Hufford, 2008), comprises multiple study designs that are defined by the assessment of psychologically relevant variables in participants' everyday lives. Prominent examples include continuous passive sensing (e.g., physiology or mobile sensing data; Ebner-Priemer \& Kubiak, 2007; Harari et al., 2017; Wiernik et al., 2020), repeated momentary assessments of participants' experiences (experience sampling; Csikszentmihalyi \& Larson, 2014), daily and weekly diary (Bolger, Davis, \& Rafaeli, 2003), and the day reconstruction method (Kahneman, Krueger, Schkade, Schwarz, \& Stone, 2004; Lucas, Wallsworth, Anusic, \& Donnellan, 2020). Experience sampling methodology (ESM) is used particularly often as it allows the momentary assessment of participants' (usually self-reported) states as they occur or shortly after their occurrence in everyday life. For instance, Fleeson (2001) conducted ESM studies with multiple daily assessments for several days to examine within- and between-person variation and density distributions of momentary personality states (e.g., state extraversion). When conducting ESM 
studies, multiple methodological choices need to be made that allow tailoring the study design to the research questions of interest (for an overview, see Horstmann, 2020).

Contrary to studies using ambulatory assessment, laboratory studies do not capture participants in their natural everyday environments (although some may seek to create 'naturalistic' environments). While this may result in decreased generalizability to people's daily lives, laboratory studies provide a more controlled setting, allow rich multivariate assessments (including data sources that are currently difficult or impossible to tap in everyday life), and facilitate causal inference if experimental manipulations are introduced. A wide range of study designs can be realized in the laboratory, including, for instance, social interaction studies (e.g., round-robin designs; Warner, Kenny, \& Stoto, 1979), behavioural tasks (e.g., learning tasks, decision-making tasks, economic games; see, e.g., Bódi et al., 2009; Buelow \& Suhr, 2009; Forsythe, Horowitz, Savin, \& Sefton, 1994), and experimental designs (Revelle, 2007; e.g., randomized presentation of certain situations or situational features). Laboratory studies can be specifically designed to capture a personality process of interest in a more controlled and potentially more finegrained manner than is possible in everyday life. For instance, Blain, Sassenberg, Xi, Zhao, and DeYoung (2019) examined the association between behavioural reward sensitivity and extraversion using a probabilistic reward task. Jach and Smillie (2020) used a novel laboratory task to examine whether openness/intellect is associated with information seeking as proposed by DeYoung (2013). As another example, Hyatt, Weiss, Carter, Zeichner, and Miller (2018) examined whether the relationship between narcissism and a measure of aggression differed between two experimental conditions: competitive or non-competitive interaction with a confederate (given the potential relevance of competitive contexts for narcissism manifestations).

Finally, long-term panel studies (e.g., Scherpenzeel, 2011; Taylor, Brice, Buck, \& Prentice-Lane, 1993; Wagner, Frick, \& Schupp, 2007) can be used to examine longer-term personality dynamics such as personality development and its sources (e.g., Denissen, Luhmann, Chung, \& Bleidorn, 2019; Roberts et al., 2006). While long-term panel studies are often limited to repeated self-report assessments, they can include other data sources and can be combined with other study types. For instance, the Personality Change Consortium explicitly highlighted the importance of frequent multi-method assessments of traits, states, and environments for understanding personality development (Bleidorn et al., 2020). One example of a partial realization of this approach is a study by Borghuis et al. (2018) which combined yearly personality assessments with daily diary measurement bursts to examine associations between positive daily experiences and personality trait change.

\section{Data sources}

Research on short-term personality dynamics requires the assessment of relevant state variables. Many studies assess affective and emotional states (e.g., Schimmack, 2003; for an overview, see Brose, Schmiedek, Gerstorf, \& Voelkle, 2020) or personality states with Big Five or HEXACO content (e.g., Fleeson, 2001; Sherman, Rauthmann, Brown, Serfass, \& Jones, 2015; for an overview, see Horstmann \& Ziegler, 2020). However, research in this area is not limited to these constructs and it may be necessary to assess more specific state variables tailored to the personality process of interest (e.g., interest and confusion in response to specific stimuli when examining openness dynamics; Fayn, Silvia, Dejonckheere, Verdonck, \& Kuppens, 2019). Importantly, state measures are not limited to self-report questionnaires. In fact, the 
study types described above can be combined with multiple data sources for the assessment of dynamic personality phenomena (Wrzus \& Mehl, 2015). Rauthmann (2017) proposed the BIOPSIES data sources: behaviour and its traces (objectively measured), indirect measures, observations, physio-biological measures (including neurobiological, imaging, and genetic data), strangers' impressions, informant knowledge, experience sampling, and self-reports ${ }^{3}$. A combination of multiple appropriate data sources is likely to yield a more comprehensive and accurate picture of a person's momentary states and enduring traits. In a notable example, Geukes et al. (2019) combined ambulatory and laboratory assessments and included a variety of data sources (e.g., behavioural observation in the laboratory, implicit personality tests, experience sampling with self- and partner-reported behaviours and interpersonal perceptions, informant reports, and other- reports in a zero acquaintance round-robin design).

In general, the field of personality dynamics has considerably profited, and will continue to do so, from advancements in innovative technologies. Beyond experience sampling and related methods, novel technologies create the possibility of collecting data in daily life from various other sources (Wiernik et al., 2020), such as passively sensed psychophysiological data (Ebner-Priemer \& Kubiak, 2007); phone usage, GPS, and accelerometer data (Harari et al., 2017); microphone data (Mehl, 2017); or wearable camera data (Blake, Lee, De La Rosa, \& Sherman, 2020). For instance, van Halem, Van Roekel, Kroencke, Kuper, and Denissen (2020) used wearables to examine the relations between skin conductance and affect in everyday life. In another study, Harari et al. (2020) used smartphone sensing (capturing conversation behaviour from microphone sensors, calls, text messages, and social media messaging app usage from phone logs) to study predictors and personality correlates of daily social behaviours.

To gain a fuller picture of human functioning, it is important to assess not only variables pertaining to the person but also to the environment (Rauthmann, 2020a). The assessment of situational variables has made substantial progress over the last decade (Horstmann, Rauthmann, \& Sherman, 2018; Rauthmann et al., 2020; Rauthmann \& Sherman, 2020). Same as for the assessment of states, different types of information and data sources are relevant for the assessment of situations. For instance, Rauthmann (2015) distinguishes multiple types of situational information (cues = physically existing, nominal objects in the situation; characteristics = subjective perceptions and meanings of cues along psychologically relevant continuous dimensions; classes $=$ groups or types of situations with similar levels or profiles of cues and/or characteristics) and informants (in situ = directly in the situation and affected by it; juxta situm = bystander to the situation of someone else; ex situ = external coder). For example, Sherman et al. (2015) investigated the relations between subjectively perceived situation characteristics and HEXACO personality states using experience sampling. Further, situational information can also be assessed using novel technologies such as mobile sensing methods (Harari, Müller, \& Gosling, 2018). In an exemplary study, Müller (2019) used GPS sensors to examine the places where participants spent time in their everyday lives. In sum, a variety of data sources can be combined with multiple study designs to provide an integrated assessment of a person's states and situations.

\footnotetext{
${ }^{3}$ Several intensive longitudinal studies use self-reported experience sampling data and thus mix BIOPSIES data sources.
} 


\section{Measurement issues}

The measurement of dynamic variables is associated with several challenges that require attention. The psychometric properties of the personality state measures used are often unclear (for an overview and considerations on the construction of state measures, see Horstmann \& Ziegler, 2020). Such personality state measures are typically created ad hoc by rephrasing personality trait measures without further validation. This can lead to potential problems such as the limited applicability of certain items in certain situations (e.g., being quiet vs. talkative may not be relevant or have a different meaning in situations where no interaction partners are present). Moreover, it is crucial that the reliability (computed within and between persons) and validity (content, structural, convergent, discriminant, and criterion validity) of personality state measures are investigated and ensured (e.g., Horstmann \& Ziegler, 2020; for a good example, see Halvorson et al., 2020). The psychometric properties of measures from other data sources should be evaluated as well. For instance, the reliability of individual differences in some behavioural task measures (e.g., Dang, King, \& Inzlicht, 2020) and physiological measures (e.g., task-based fMRI; Elliot et al., 2019) has been questioned. In general, the psychometric properties of variables from novel data sources are often unknown, and terminological ambiguities across disciplines pose additional complications. Given these issues, it is important that researchers pay attention to the psychometrically rigorous measurement of states and situations across all data sources.

\section{Sampling}

For dynamics-focused studies, it is crucial to pay attention to the sampling of persons and situations (e.g., Wrzus \& Mehl, 2015) as well as relevant state variables ${ }^{4}$. Concerning the sampling ofpersons, sufficient variability in the measure of interest is required to examine between-person associations. Representatively drawn samples of persons are preferable to maximize diversity and generalizability, albeit not always feasible. Additionally, it may be desirable to specifically target certain groups of participants (e.g., extreme groups or clinical samples) for a given research question. For instance, Ringwald, Hallquist, Dombrovski, and Wright (2020) examined affect and interpersonal behaviour variability using ambulatory assessment in individuals meeting the criteria for borderline personality disorder. Finally, it should be noted that a sufficiently large number of participants needs to be sampled to obtain precise parameter estimates.

Regarding the sampling of situations, the types of situations assessed, the number of occasions for each participant, and the timing of assessments have to be considered. First, the importance of representative sampling of situations has been emphasized (e.g., Blum et al., 2018; Horstmann, Ziegler, \& Ziegler, 2018; Judd, Westfall, \& Kenny, 2012). Selective sampling of situations may lead to biased results and yields an incomplete picture of person-environment relations (Rauthmann, 2020a). When sampling situations, researchers should specify the population of target situations (e.g., daily life situations, interpersonal situations, work situations), and situations sampled should be representative of this population. When focusing on specific types of situations (e.g., interpersonal situations), targeting the situations of interest can be facilitated, for example, by conducting event-contingent experience sampling studies (e.g., Geukes et al., 2019) or by

\footnotetext{
${ }^{4}$ The sampling of relevant trait variables is important as well, but here we focus on states given their particular importance for dynamics-focused studies.
} 
employing specifically designed laboratory studies. For example, when sampling situations that not everyone encounters, researchers can attempt to experimentally create these situations in the laboratory or using virtual reality. Systematic taxonomies of situational cues or classes (e.g., Rauthmann et al., 2015) could aid researchers in determining whether their sampled situations have situation cue/class frequency distributions similar to the population of interest. Second, a sufficient number of situations per person as well as sufficient situational variability are necessary for the precise estimation of effects of interest (e.g., individual differences in within-person associations; Neubauer, Voelkle, Voss, \& Mertens, 2020). Third, the timing of assessments needs to be tailored to the research question of interest. For instance, when examining changes or transactions over time, it is crucial to sample data at the appropriate frequency (i.e., number of assessments per time unit; e.g., Bleidorn et al., 2020; Wrzus \& Mehl, 2015). While passive sensing (e.g., Harari et al., 2017) is continuous and often unobtrusive, sampling intervals have to be specified for self-report data. For example, Rauthmann, Jones, and Sherman (2016) examined cross-lagged associations between self-reported situation characteristics and personality states, each at least an hour apart from each other, and reported only very small cross-lagged effects. Given that causal transaction effects are very likely (people's states likely change in response to [changes in] perceived situations), these findings may be attributable to the low sampling frequency (i.e., hours rather than minutes). In a similar vein, research on long-term dynamics (i.e., personality development) has emphasized the importance of examining effects on relevant timescales to accurately measure and distinguish various forms of change (e.g., anticipatory change, post-event change, reversible change; Denissen et al., 2019; Luhmann, Orth, Specht, Kandler, \& Lucas, 2014). Thus, appropriate study designs should be implemented that allow investigating processes of interest on the timescales on which they actually occur.

Researchers also need to decide on the sampling of relevant state variables. ${ }^{5}$ This includes decisions pertaining to the breadth vs. narrowness of assessed dependent and independent state variables (see bandwidth-fidelity trade-off; Cronbach \& Gleser, 1957; e.g., Big Five domain states vs. Big Five facet states vs. specific, narrower state variables). Moreover, researchers need to decide which types of state variables to include (e.g., cognition, emotion, motivation, behaviour) and which data sources to use (e.g., selfreport, passive mobile sensing, physiological measures). The number of relevant variables assessed can be increased without undue participant burden through the use of passive measures (e.g., Harari et al., 2017; Wiernik et al., 2020) and using planned missingness designs (e.g., for self-reported states; Horstmann, 2020; Silvia, Kwapil, Walsh, \& MyinGermeys, 2014).

Another crucial topic concerning sampling in dynamics-focused studies is the issue of statistical power. Researchers should design their studies to yield sufficient power for testing their hypothesis - which can have different implications depending on the type of hypothesis (e.g., between- vs. within-person). Power analysis for intensive longitudinal studies is more complex than for simple statistical tests such as $t$-tests and correlations. For example, in multilevel models that are typically fitted in ESM studies, statistical power depends on many parameters such as the number of persons and assessments, random slope variance, intraclass correlation, and fixed effects. For relevant guides and tools, see, for example, Arend and Schäfer (2019), Scherbaum and Pesner (2019), and Lafit et al.

\footnotetext{
${ }^{5}$ Of course, in research examining person-environment relations, one also needs to pay attention to sampling relevant situational variables (e.g., specific situation characteristics).
} 
(2020). Generally, power analyses should be tailored to the type of effect of interest. Power for between-person effects and cross-level interactions depends more strongly on the number of participants than power for within-person effects. For examples of recent ESM studies on personality dynamics reporting power analyses, see Horstmann, Rauthmann, Sherman, and Ziegler (2020), Kritzler, Krasko, and Luhmann (2020), and Kroencke, Geukes, Utesch, Kuper, and Back (2020).

\section{Statistical approaches}

The typically longitudinal data suitable to investigate personality dynamics requires appropriate statistical tools during analysis. Various approaches such as multilevel modelling (e.g., Hox, Moerbeek, \& van de Schoot, 2010), structural equation modelling (e.g., Kline, 2016), network models (e.g., Epskamp, Waldorp, Mõttus, \& Borsboom, 2018), and dynamic system models (e.g., Sosnowska, Kuppens, De Fruyt, \& Hofmans, 2019) have been proposed and applied. Table 3 gives a selective overview of relevant statistical approaches, sample work introducing or discussing these approaches (e.g., methodological articles) as well as sample studies applying them. ${ }^{6}$

The various analysis techniques fulfil different goals and sometimes map onto corresponding theoretical approaches (see Tables 2 and 3). However, they have in common that they allow the modelling of nested data (i.e., measurement occasions nested in participants). One key difference between analysis techniques is the treatment of time. Some analysis approaches model variability across measurement occasions but conceptualize occasions as independent within persons (e.g., in multilevel modelling, although autocorrelated residuals can be estimated). On the other hand, certain analysis approaches specifically model change over time (e.g., dynamic system models; Sosnowska et al., 2019; the computational cues-tendency-action model; Revelle \& Condon, 2015). Despite the differences between analysis techniques with respect to the treatment of time, it should be emphasized that the presented approaches are often highly flexible and many of them allow for the modelling of time. For instance, lagged effects representing associations or transactions over time can be included in several of the presented approaches (e.g., multilevel modelling, structural equation models, temporal network models). Some authors have emphasized the centrality of explicitly modelling time-dependent processes when seeking to investigate dynamics (e.g., Revelle \& Wilt, 2020).

One issue worth mentioning is to which degree different analysis techniques truly model or capture dynamic phenomena. Some may argue that the term 'dynamic' should be reserved for studies modelling time-dependent processes, while others may, for instance, also regard intra-individual associations of variables as dynamic. This issue becomes particularly apparent when multi-occasion data is reduced to individual difference indices (e.g., Dejonckheere et al., 2019; Wendt et al., 2020): While individual differences in autocorrelations between states and even state variability may be considered dynamic, extracting a person mean of states could be considered a different method to capture a static phenomenon. Future work may benefit from more terminological precision in this respect (see also Future Directions and Desiderata).

\footnotetext{
${ }^{6}$ Another noteworthy family of models are variance partitioning approaches (generalizability theory; Cronbach et al., 1972), which Furr (2020) emphasized for the analysis of variability and consistency in behaviour. While variance components are frequently estimated in personality dynamics research (e.g., using multilevel modelling), classical generalizability theory is currently only infrequently applied. Therefore, this approach is not included in Table 3.
} 


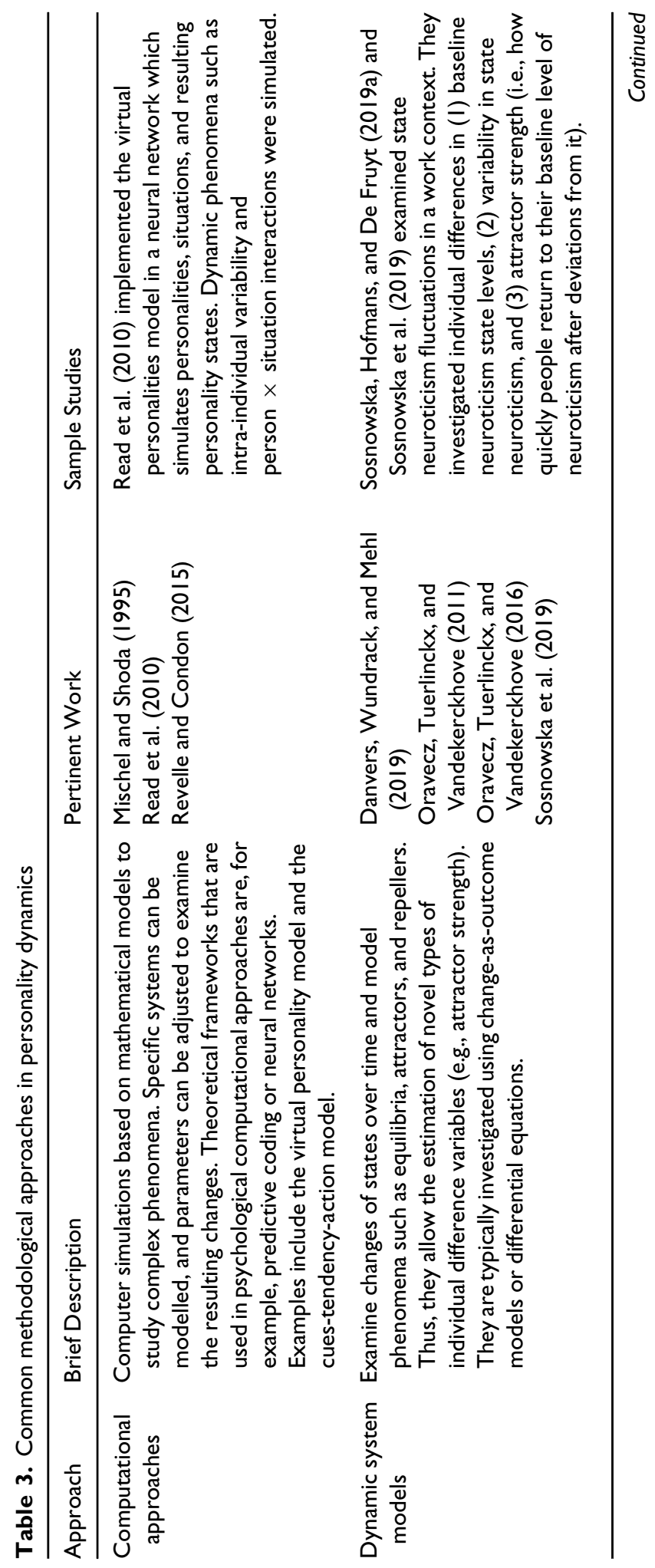




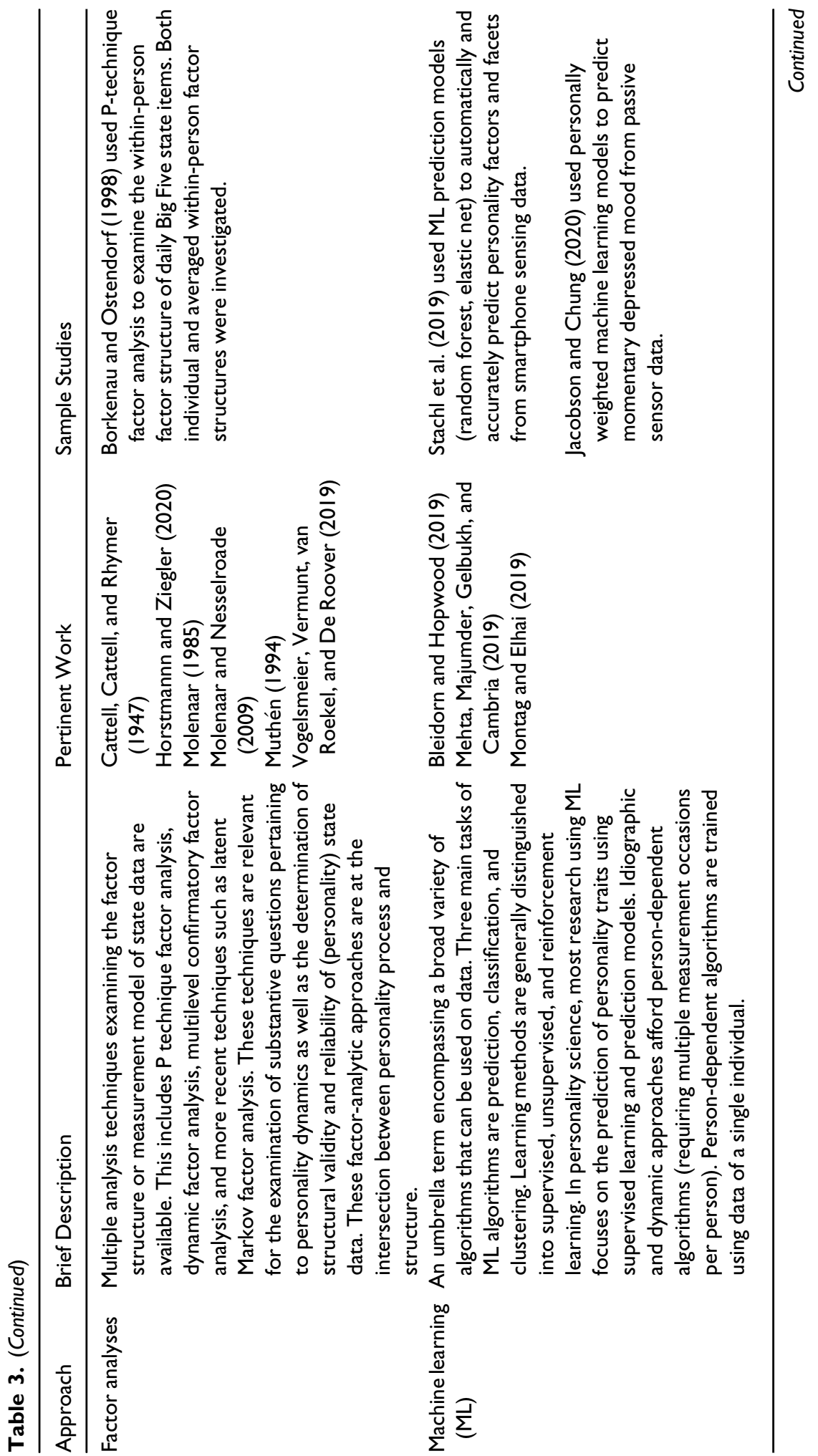




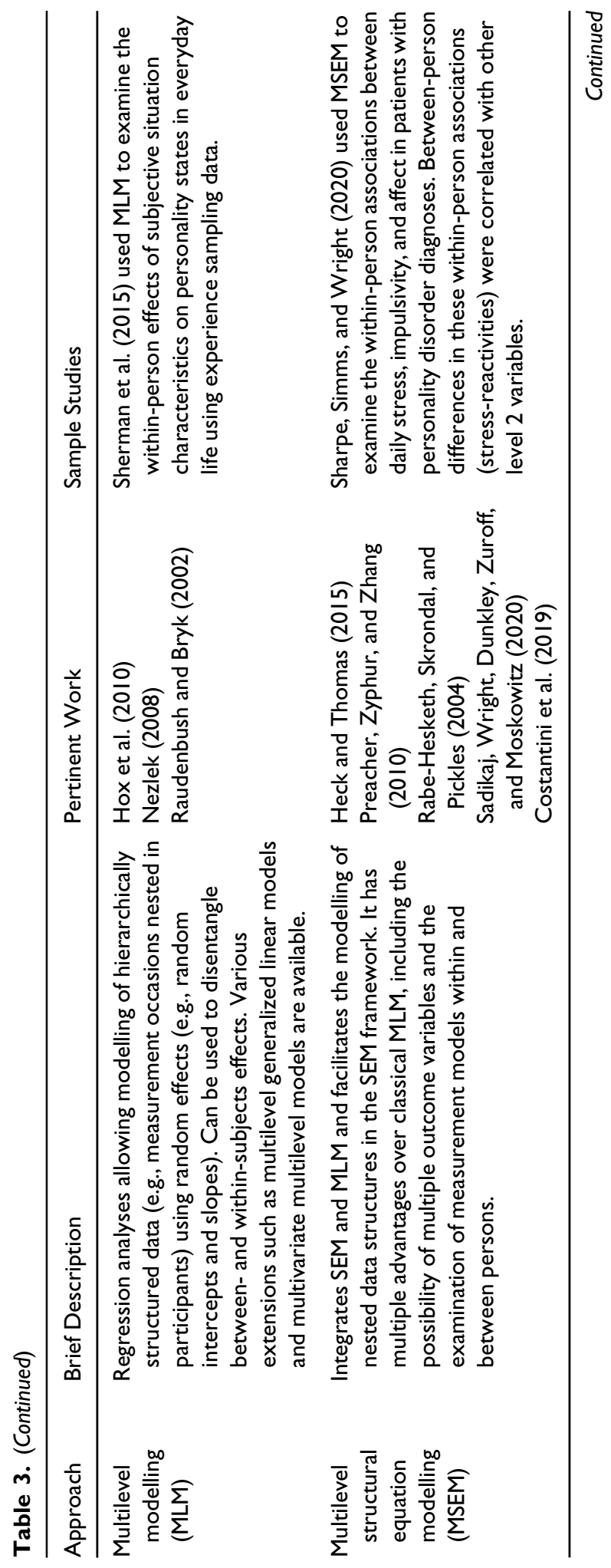




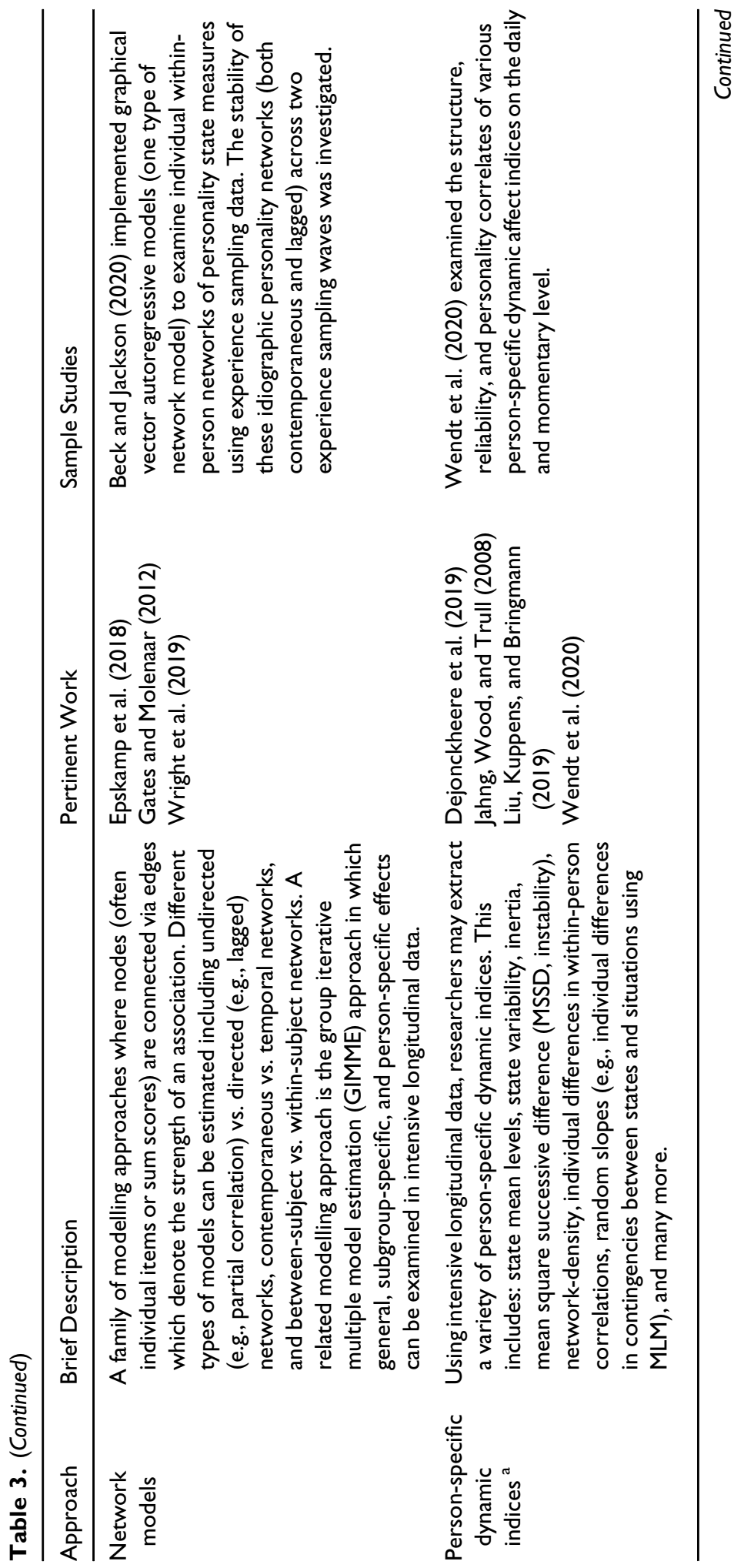




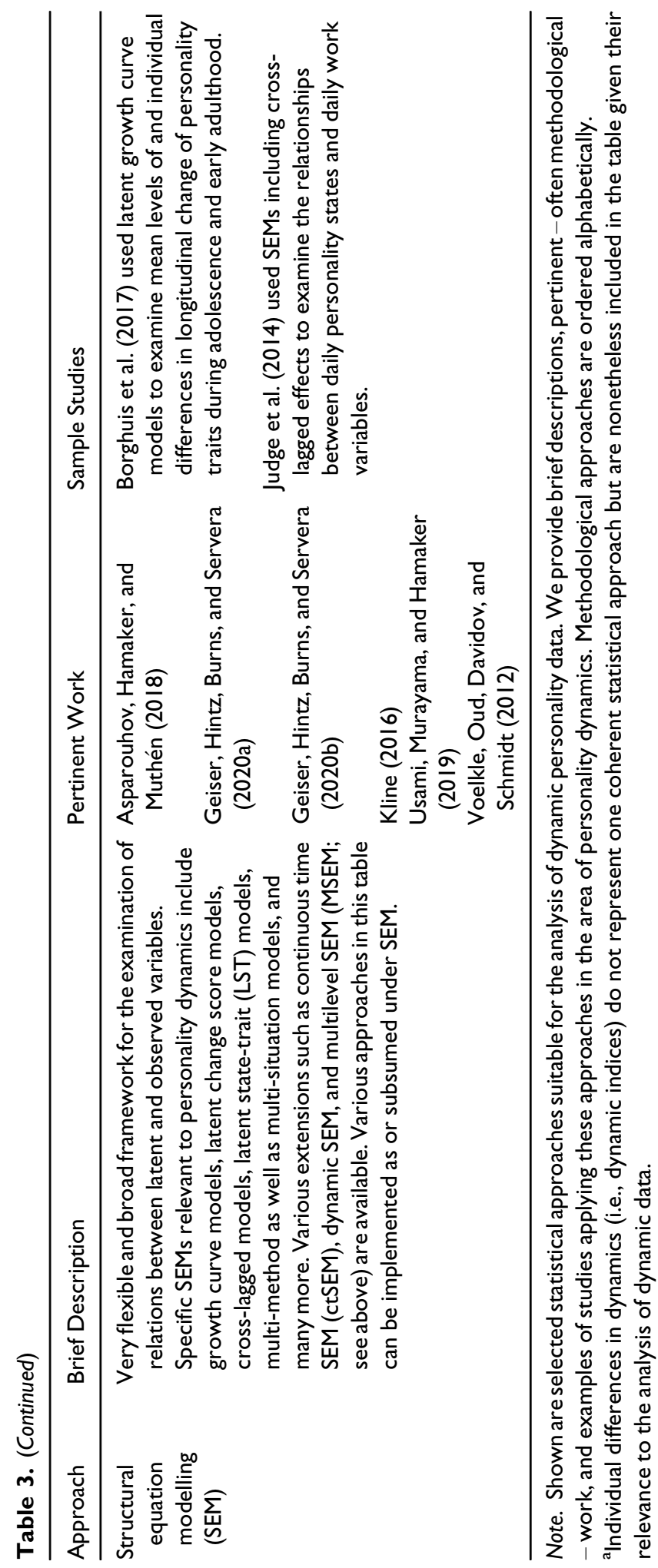


Multiple statistical approaches allow distinguishing inter-individual effects (betweenperson: e.g., extraverted individuals report higher typical or average momentary wellbeing) from intra-individual effects (within-person: e.g., momentary deviations from one's typical state extraversion are associated with momentary deviations from one's typical well-being). For instance, multilevel modelling allows the examination of within-person associations between variables as well as individual differences therein (i.e., random slopes). Individual differences in within-person contingencies have been emphasized in various theories (e.g., Fleeson \& Jayawickreme, 2020; Mischel \& Shoda, 1995). When these are predicted by personality traits, this represents so-called cross-level interactions (i.e., the level 2 variable, a personality trait, moderates the level 1 association between two state variables). For example, Sherman et al. (2015) examined whether links between situation characteristics and personality states were moderated by personality traits and found only few interaction effects.

Beyond the specific statistical approaches presented in Table 3, it should be mentioned that the intensive longitudinal data gathered in personality dynamics research allow both idiographic (i.e., individual-specific) and nomothetic modelling (i.e., generalizing across individuals). Multiple authors have noted the importance of idiographic approaches in psychology (e.g., Allport, 1937, 1962; Beck \& Jackson, 2020; Molenaar, 2004), and some have emphasized the viability of combining idiographic and nomothetic work (e.g., Beltz, Wright, Sprague, \& Molenaar, 2016; Revelle \& Wilt, 2020; Wright \& Zimmermann, 2019). Thus, various suitable statistical approaches exist and, together with other methodological advances, facilitate the study of dynamic phenomena.

\section{Personality dynamics in applied settings}

In the following paragraphs, we selectively showcase some applications to briefly illustrate the benefits of a dynamic approach to individual differences and refer to relevant publications. We focus on research and practice in clinical psychology/psychotherapy and work/organizational psychology as major applied disciplines in psychological science. Studies on dynamic personality phenomena in educational settings also exist (e.g., Cervone, Mercurio, \& Lilley, 2020; Zhang, Beckmann, \& Beckmann, 2019) but remain sparse.

\section{Clinical psychology}

Contemporary theories and models of psychopathology generally emphasize the relevance of dynamic processes underlying maladaptive functioning (e.g., DeYoung \& Krueger, 2018; Hopwood, 2018; Pincus, 2005; Pincus \& Hopwood, 2012; Ringwald, Woods, Edershile, Sharpe, \& Wright, 2020; Wright et al., 2020). For example, Carver, Johnson, and Timpano (2017) suggested a process-based, functional interpretation of the recently proposed general factor of psychopathology (p factor; e.g., Caspi et al., 2014). Also, psychotherapy centres on the premise that psychopathology is dynamic by nature and that dysfunctional patterns of experience and behaviour can be disrupted or modified to achieve higher levels of functioning. We believe personality dynamics theory and research can inform the study and treatment of all psychopathologies (e.g., DeYoung et al., 2020), but we will focus on personality disorders (PDs) which constitute an obvious link between personality and psychopathology. 
The dynamics of PDs can be examined at different time scales, nomothetically or idiographically, and across or within situations (Hopwood, 2018; Hopwood, Zimmermann, Pincus, \& Krueger, 2015; Ringwald, Woods, et al., 2020). First, the long-term development of PDs, for example, the stability of pathological traits and symptoms, is of theoretical and practical relevance (e.g., Hopwood et al., 2013; see also Hopwood \& Bleidorn, 2018 for a review). Second, some PDs can be defined by dysfunctional patterns of within-person variability across situations. Narcissistic PD, for instance, can be characterized by alternating states of idealization and devaluation (e.g., Cain, Pincus, \& Ansell, 2008). Third, PDs can be nomothetically examined in terms of their characteristic contextualized response patterns or situational contingencies. For example, in narcissists, antagonistic behaviour and negative affect may often be triggered by perceiving others as dominant (Wright et al., 2017). Fourth, practitioners can idiographically explore patients' unique dysfunctional dynamics and symptom triggers and tailor interventions accordingly (Hopwood et al., 2015; Wright \& Zimmermann, 2019; Zimmermann et al., 2019). Fifth, in psychotherapy, insights gained by zooming into the moment-to-moment dynamics that unfolded within a single relevant situation in the patient's life may be beneficial (Hopwood, 2018; Hopwood et al., 2015). Finally, a process-oriented conceptualization of personality may also enable the integration of the clinical and personality psychological literatures (Ringwald, Woods, et al., 2020).

\section{Work and organizational psychology}

A dynamic perspective on personality offers great potential for work and organizational psychologists (Beckmann \& Wood, 2020) and has been applied to study, for example, job satisfaction (Ilies \& Judge, 2002), work motivation (Judge, Simon, Hurst, \& Kelley, 2014), emotions at work (Fisher, Minbashian, Beckmann, \& Wood, 2013; Thapa et al., 2020), or the influence of work experiences on personality trait change (Li et al., 2020; Wille \& De Fruit, 2014). Here, we illustrate the utility of dynamic approaches by focusing on the personality-performance link.

Predicting performance is especially relevant in personnel selection, and considering dynamic personality phenomena may have practical benefits (see Sosnowska, Hofmans, \& Lievens, 2020). For example, recent empirical studies suggest that assessing stable interindividual differences in within-person contingencies (Mischel \& Shoda, 1995; see CAPS in Table 3) between personality states and situational demands (i.e., state levels changing systematically with task demand) may improve predictions of work outcomes beyond traditional personality trait assessments (Minbashian, Wood, \& Beckmann, 2010; Wood et al., 2019). Moreover, several studies have investigated relations between personality state fluctuations and job performance (e.g., Debusscher, Hofmans, \& De Fruyt, 2014, 2016a, 2016b, 2017; Sosnowska et al., 2019b). Guided by Whole Trait Theory (Fleeson \& Jayawickreme, 2015; see WTT in Table 3), Lievens et al. (2018) used situational judgement tests to examine people's hypothetical states in response to different work situations and found that intra-individual variability incrementally predicted job performance beyond traditional trait measures. Importantly, variability in situational judgement test responses was correlated with (i.e., validly generalized to) personality state fluctuations in everyday life.

In sum, if these findings prove replicable, dynamic within-person phenomena, such as situational contingencies and state fluctuations, may be relevant individual difference variables and predictors in work settings. Further, existing personnel selection methods 
may be well suited or could easily be adapted to study these phenomena (Lievens, 2017; Sosnowska, Kuppens, Kuppens, De Fruyt, \& Hofmans, 2020).

\section{Future directions and desiderata}

Although a dynamic understanding of personality goes back to the beginnings of psychology itself, interest in personality dynamics has been reinvigorated in the recent two decades and the field has experienced a renaissance. Thus, personality dynamics is still actually a nascent field where multiple desiderata can be identified. Here, we formulate some future directions that could help the field move forward.

First, a pervasive issue in personality psychology - and thus also in personality dynamics research - is the over-reliance on self-report data and the narrow focus on traits, often in the form of the Big Five. Many studies purport to have examined personality change or fluctuations in personality states with such data. However, what these studies may really have examined were changes in explicit self-concepts (e.g., self-reported extraversion) across time, or momentarily activated construals or self-schemata (e.g., selfreported extraverted behaviour), often even retrospectively assessed from memory. While such studies provide valuable insights into how people construe themselves and how self-concepts may be malleable, it is overstretching to equate explicit self-concepts with personality traits or personality as a whole. Moving forward, different data sources (e.g., actual and observed behaviour, indirect measures, biophysiological measures, otherreports) should be used, ideally simultaneously, to tease apart generalizable patterns from more data source-specific ones.

Second, personality states are an integral concept to studying personality dynamics. However, most personality state measures have been developed in an ad hoc fashion by abridging trait measures, and their psychometric properties are often unknown. It will be important to create psychometrically validated personality state measures, ideally using multiple data sources (e.g., self- and other-reports, actual behaviour sensed by wearables, etc.). Additionally, the applicability of state measures in the situations sampled needs to be evaluated (e.g., some states cannot be enacted in certain situations). Finally, state measures should allow both nomothetic and idiographic analyses to be useful for dynamics-focused research endeavours.

Third, not only the measures assessing traits, states, and situations need great care, but also the sampling of persons and situations that yield data on those measures. There are two issues that should be considered: variability and generalizability. A comprehensive sampling of persons and situations is needed to ensure sufficient variability for statistical analyses (e.g., variance partitioning or multivariate analyses). Moreover, we often want observed effects to generalize beyond the specific sample of persons and situations and the methods used, or at least understand their constraints on generality (Simons, Shoda, \& Lindsay, 2017). Hence, future research should carefully attend to the diversity and potential generalizability of the samples of persons and situations, and of the methods used.

Fourth, within-person dynamics (e.g., within-person variability or within-person contingencies) as individual difference variables or personality units require further examination. Some parameters of within-person dynamics have demonstrated low to moderate between-person reliabilities (e.g., Jones, Brown, Serfass, \& Sherman, 2017; Neubauer et al., 2020; Wendt et al., 2020; Wood et al., 2019). However, further work is needed to establish which within-person dynamics constitute stable and consequential 
individual differences, and under which conditions. For one, it remains to be seen when and to what extent within-person parameters add information beyond person mean levels. This pertains to their incremental validity, for example, in the prediction of trait levels, well-being, and important outcomes such as job performance (see Personality dynamics in applied settings). So far, research suggests that individual differences in within-person dynamics, as currently assessed, may add only limited predictive value beyond person mean levels (e.g., Dejonckheere et al., 2019; Wendt et al., 2020; cf. Wood et al., 2019).

Fifth, we have restricted this review to short- and middle-term dynamics. However, as mentioned above, there is ample work on long-term dynamics, most notably in recent research on the processes underlying personality development (Bleidorn et al., 2020; Wrzus, 2020), including trait change following interventions (Hudson, 2020). An integration of dynamics in the origins, expressions, outcomes, and development of personality at different timescales (see also the discussion of timescales in Sampling above) can move us towards a more holistic understanding. There is already promising research attempting such integration (e.g., longitudinal multi-burst designs: Borghuis et al., 2018; Quintus, Egloff, \& Wrzus, 2020) and there are proposals for future research (e.g., longitudinal experience-wide association studies: Bleidorn et al., 2020). For instance, Quintus et al. (2020) examined in one study (1) how traits are related to situation characteristics and states, (2) how states and situation characteristics are related at the momentary within-person level, and (3) how aggregated state changes are related to trait changes across longer time scales. Innovations in optimizing and automating longitudinal intensive data collection and analysis will likely advance the study of personality dynamics at different timescales.

Sixth, future research needs to put a stronger emphasis on conceptual clarity, terminological accuracy and consistency, and operationalization to move towards formalizable theories. We compiled key concepts and terms in Table 1, but we do note that there is considerable heterogeneity in the literature of how exactly the terms are used. For example, some authors lump different phenomena under the term 'process' (jingle fallacy), while others use different labels for 'process' (jangle fallacy). This impedes clear and consistent communication as well as a cumulative synthesis of the literature. Further, unclear or fuzzy concepts are often difficult to translate into a coherent operationalization. For example, operationalization issues can occur when a concept is not properly identified conceptually or is not well implemented into a corresponding measure to tap it. $^{7}$ Problematic operationalization, in turn, hampers the testing and formalization of theories. Integrated theory formation that cuts across literatures will be vital to the field of personality dynamics (which is currently rather fragmented with several different theoretical approaches; see Table 2), and thus, more terminological precision, operationalization, and formalization will be key goals to pursue.

Lastly, dynamics-focused research will also benefit from best practices in open science to ensure transparency, reproducibility, and replication. This includes attending to high statistical power for detecting also subtle effects with sufficient precision and being able to replicate research. Moreover, it includes the wider use of pre-registration as well as registered reports.

\footnotetext{
${ }^{7}$ Further, to complicate matters even more, the measures may be used in inappropriate designs (e.g., problematic sampling of persons and/or situations) and inappropriate statistical procedures may be applied to the data.
} 


\section{Conclusion}

The study of personality dynamics is a vibrant field that has enjoyed increasing interest and advances in the last decades. Further progress in this field will complement other psychological research that also seeks to understand the mechanisms and processes underlying human experience and behaviour - one of the main goals of psychological science. As we have shown in this primer, personality dynamics research covers a staggering range of concepts, theories, and methods which may have to be integrated better moving forward. We hope this review is not only a serviceable overview of the field but can also entice scholars interested in personality dynamics to delve into this fascinating field and contribute to it.

\section{Conflicts of interest}

All authors declare no conflict of interest

\section{Author contributions}

Niclas Kuper (Conceptualization; Writing - original draft) Nick Modersitzki (Conceptualization; Writing - original draft) Le Vy Phan (Conceptualization; Writing - original draft) John Rauthmann, Ph. D. (Conceptualization; Supervision; Writing - review \& editing).

\section{References}

Adler, J. M. (2012). Living into the story: Agency and coherence in a longitudinal study of narrative identity development and mental health over the course of psychotherapy. Journal of Personality and Social Psychology, 102, 367-389. https://doi.org/10.1037/a0025289

Allen, J. L., Sylaska, K., \& Mayer, J. D. (2020). Dynamic pathways of personality: a further development of the personality systems framework. In J. F. Rauthmann (Ed.), Handbook of personality dynamics and processes, 1st ed. Amsterdam, The Netherlands: Elsevier.

Allport, G. W. (1937). Personality: A psychological interpretation. New York, NY: H. Holt and Company.

Allport, G. W. (1962). The general and the unique in psychological science. Journal of Personality, 30, 405-422. https://doi.org/10.1111/j.1467-6494.1962.tb02313.x

Allport, G. W. (1968). The person in psychology: Selected essays. Boston, MA: Beacon Press.

Allport, G. W., \& Vernon, P. E. (1930). The field of personality. Psychological Bulletin, 27, 677-730. https://doi.org/10.1037/h0072589

American Psychological Association. (n.d.-a). Development. In Dictionary of Psychology. Retrieved from https://dictionary.apa.org/development. accessed July 12, 2020

American Psychological Association. (n.d.-b). Dynamic. In Dictionary of Psychology. Retrieved from https://dictionary.apa.org/dynamic. accessed July 12, 2020

American Psychological Association. (n.d.-c). System. In Dictionary of Psychology. Retrieved from https://dictionary.apa.org/system. accessed July 12, 2020

Apter, M. J. (1982). The experience of motivation: The theory of psychological reversals. London, UK: Academic Press.

Apter, M. J. (1984). Reversal theory and personality: A review. Journal of Research in Personality, 18, 265-288. https://doi.org/10.1016/0092-6566(84)90013-8

Apter, M. J. (2001). Reversal theory as a set of propositions. In M. Apter (Ed.), Motivational styles in everyday life: A guide to reversal theory (pp. 37-51). New York, NY: American Psychological Association. http://doi.org/10.1037/10427-002 
Apter, M. J. (2013). Developing reversal theory: Some suggestions for future research. Journal of Motivation, Emotion, and Personality, 1(1), 1-8. https://doi.org/10.12689/jmep.2013.101

Arend, M., \& Schäfer, T. (2019). Statistical power in two-level models: a tutorial based on monte carlo simulation. Psychological Methods, 24, 1-19. https://doi.org/10.1037/met0000195

Asendorpf, J. B. (2020). Modeling developmental processes. In J. F. Rauthmann (Ed.), Handbook of personality dynamics and processes, 1st. ed. Amsterdam, The Netherlands: Elsevier.

Asparouhov, T., Hamaker, E. L., \& Muthén, B. (2018). Dynamic structural equation models. Structural Equation Modeling: A Multidisciplinary Journal, 25, 359-388. https://doi.org/10. 1080/10705511.2017.1406803

Atkinson, J. W., \& Birch, D. (1970). The dynamics of action. Hoboken, NJ: Wiley.

Back, M. D. (2018). The narcissistic admiration and rivalry concept. In A. D. Hermann, A. B. Brunell \& J. D. Foster (Eds.), Handbook of trait narcissism (pp. 57-67). New York, NY: Springer. http:// doi.org/10.1007/978-3-319-92171-6_6

Back, M. D. (2020). Social Interaction Processes and Personality. In J. F. Rauthmann (Ed.), Handbook of personality dynamics and processes, 1st ed. Amsterdam, The Netherlands: Elsevier.

Back, M. D., Baumert, A., Denissen, J. J. A., Hartung, F.-M., Penke, L., Schmukle, S. C., .. Wrzus, C. (2011). PERSOC: A unified framework for understanding the dynamic interplay of personality and social relationships. European Journal of Personality, 25, 90-107. https://doi.org/10. 1002/per.811

Back, M. D., Schmukle, S. C., \& Egloff, B. (2009). Predicting actual behavior from the explicit and implicit self-concept of personality. Journal of Personality and Social Psychology, 97, 533548. https://doi.org/10.1037/a0016229

Bandura, A. (1986). Social foundations of thought and action: A social cognitive theory. Upper Saddle River, NJ: Prentice Hall.

Bandura, A. (1999). Social cognitive theory of personality. In D. Cervone \& Y. Shoda (Eds.), The coberence of personality: Social-cognitive bases of consistency, variability, and organization (pp. 185-241). New York, NY: Guilford Press.

Baumann, N., \& Kuhl, J. (2020). PSI Theory in Action: The assessment of self-competences as an aid in counseling and therapy. In J. F. Rauthmann (Ed.), Handbook of personality dynamics and processes, 1st ed.). Amsterdam, The Netherlands: Elsevier.

Baumert, A., Schmitt, M., Perugini, M., Johnson, W., Blum, G., Borkenau, P., . . Mõttus, R. (2017). Integrating personality structure, personality process, and personality development. European Journal of Personality, 31, 503-528. https://doi.org/10.1002/per.2115

Beck, E. D., \& Jackson, J. J. (2020). Consistency and change in idiographic personality: A longitudinal ESM network study. Journal of Personality and Social Psychology, 118, 1080-1100. https:// doi.org/10.1037/pspp0000249

Beckmann, N., \& Wood, R. E. (2020). Dynamic personality at work. In Y. Griep \& S. D. Hansen (Eds.), Handbook on the temporal dynamics of organizational behavior (pp. 192-220). Edward Elgar Publishing. https://doi.org/10.4337/9781788974387.00022

Beltz, A. M., Wright, A. G., Sprague, B. N., \& Molenaar, P. C. (2016). Bridging the nomothetic and idiographic approaches to the analysis of clinical data. Assessment, 23, 447-458. https://doi. org/10.1177/1073191116648209

Blain, S. D., Sassenberg, T. A., Xi, M., Zhao, D., \& DeYoung, C. G. (2019). Extraversion but not depression predicts implicit reward sensitivity: Revisiting the measurement of anhedonic phenotypes. https://doi.org/10.31234/osf.io/vzt6d

Blake, A. B., Lee, D. I., De La Rosa, R., \& Sherman, R. A. (2020). Wearable cameras, machine vision, and big data analytics: Insights into people and the places they go. In S. E. Woo, L. Tay \& R. W. Proctor (Eds.), Big data in psychological research (pp. 125-143). New York, NY: American Psychological Association.

Bleidorn, W., \& Hopwood, C. J. (2019). Using machine learning to advance personality assessment and theory. Personality and Social Psychology Review, 23, 190-203. https://doi.org/10.1177/ 1088868318772990 
Bleidorn, W., Hopwood, C. J., Back, M., Denissen, J. J. A., Hennecke, M., Jokela, M., Zimmermann, J. (2020). Longitudinal Experience-Wide Association Studies (LEWAS) - A framework for studying personality change. https://doi.org/10.31234/osf.io/krfw9

Blum, G. S., Baumert, A., \& Schmitt, M. (2020). Personality processes - from description to explanation. In J. F. Rauthmann (Ed.), Handbook of personality dynamics and processes, 1st ed. Amsterdam, The Netherlands: Elsevier.

Blum, G. S., Rauthmann, J. F., Göllner, R., Lischetzke, T., Schmitt, M., \& Kandler, C. (2018). The nonlinear interaction of person and situation (NIPS) model: Theory and empirical evidence. European Journal of Personality, 32, 286-305. https://doi.org/10.1002/per.2138

Bodi, N., Keri, S., Nagy, H., Moustafa, A., Myers, C. E., Daw, N., .. Gluck, M. A. (2009). Rewardlearning and the novelty-seeking personality: A between-and within-subjects study of the effects of dopamine agonists on young Parkinson's patients. Brain: A. Journal of Neurology, 132(9), 2385-2395. https://doi.org/10.1093/brain/awp094

Bolger, N., Davis, A., \& Rafaeli, E. (2003). Diary methods: Capturing life as it is lived. Annual Review of Psychology, 54(1), 579-616. https://doi.org/10.1146/annurev.psych.54.101601.145030

Borghuis, J., Denissen, J. J. A., Oberski, D., Sijtsma, K., Meeus, W. H. J., Branje, S., . . Bleidorn, W. (2017). Big Five personality stability, change, and codevelopment across adolescence and early adulthood. Journal of Personality and Social Psychology, 113, 641-657. https://doi.org/10. 1037/pspp0000138

Borghuis, J., Denissen, J. J. A., Sijtsma, K., Branje, S., Meeus, W. H. J., Bleidorn, W., \& Wrzus, C. (2018). Positive daily experiences are associated with personality trait changes in middle-aged mothers. European Journal of Personality, 32, 672-689. https://doi.org/10.1002/per.2178

Borkenau, P., \& Ostendorf, F. (1998). The Big Five as states: How useful is the five-factor model to describe intraindividual variations over time? Journal of Research in Personality, 32, 202-221. https://doi.org/10.1006/jrpe.1997.2206

Brose, A., Schmiedek, F., Gerstorf, D., \& Voelkle, M. C. (2020). The measurement of within-person affect variation. Emotion, 20, 677-699. https://doi.org/10.1037/emo0000583

Buelow, M. T., \& Suhr, J. A. (2009). Construct validity of the Iowa gambling task. Neuropsychology Review, 19(1), 102-114. https://doi.org/10.1007/s11065-009-9083-4

Buss, D. M., \& Craik, K. H. (1983). The act frequency approach to personality. Psychological Review, 90, 105-126. https://doi.org/10.1037/0033-295X.90.2.105

Cain, N. M., Pincus, A. L., \& Ansell, E. B. (2008). Narcissism at the crossroads: Phenotypic description of pathological narcissism across clinical theory, social/personality psychology, and psychiatric diagnosis. Clinical Psychology Review, 28, 638-656. https://doi.org/10.1016/j.cpr.2007.09. 006

Carver, C. S., Johnson, S. L., \& Timpano, K. R. (2017). Toward a functional view of the p factor in psychopathology. Clinical Psychological Science, 5, 880-889.

Carver, C. S., \& Scheier, M. F. (1981). Attention and self-regulation: A control-theory approach to human behavior. New York, NY: Springer.

Carver, C. S., \& Scheier, M. F. (1982). Control theory: A useful conceptual framework for personality-social, clinical, and health psychology. Psychological Bulletin, 92(1), 111-135. https://doi.org/10.1037/0033-2909.92.1.111

Carver, C. S., \& Scheier, M. F. (2003). Self-regulatory perspectives on personality. In T. Millon, M. J. Lerner \& I. B. Weiner (Eds.), Handbook of psychology: Personality and social psychology (pp. 185-208). Hoboken, NJ: Wiley. https://doi.org/10.1002/0471264385.wei0508

Casadevall, A., \& Fang, F. C. (2009). Mechanistic Science. Infection and Immunity, 77, 3517-3519. https://doi.org/10.1128/iai.00623-09

Caspi, A., Houts, R. M., Belsky, D. W., Goldman-Mellor, S. J., Harrington, H. L., Israel, S., , . Moffitt, T. E. (2014). The p factor: one general psychopathology factor in the structure of psychiatric disorders? Clinical Psychological Science, 2, 119-137. https://doi.org/10.1177/ 2167702613497473 
Caspi, A., Roberts, B. W., \& Shiner, R. L. (2005). Personality development: Stability and change. Annual Review of Psychology, 56(1), 453-484. https://doi.org/10.1146/annurev.psych.55. 090902.141913

Cattell, R. B. (1946). Description and measurement of personality. New York, NY: World Book Company.

Cattell, R. B., Cattell, A. K. S., \& Rhymer, R. M. (1947). P-technique demonstrated in determining psychophysiological source traits in a normal individual. Psychometrika, 12, 267-288. https:// doi.org/10.1007/BF02288941

Cervone, D. (2004). The architecture of personality. Psychological Review, 111(1), 183-204. https://doi.org/10.1037/0033-295X.111.1.183

Cervone, D. (2008). Explanatory models of personality: Social-cognitive theories and the knowledge-and-appraisal model of personality architecture. In G. J. Boyle, G. Matthews \& D. H. Saklofske (Eds.), The SAGE bandbook of personality theory and assessment, Vol. 1. Personality theories and models (pp. 80-100). London, UK: Sage Publications, Inc. https://doi. org/10.4135/9781849200462.n4

Cervone, D. (2020). The KAPA model of personality structure and dynamics. In J. F. Rauthmann (Ed.), Handbook of personality dynamics and processes, 1st ed. Amsterdam, The Netherlands: Elsevier.

Cervone, D., \& Little, B. R. (2019). Personality architecture and dynamics: The new agenda and what's new about it. Personality and Individual Differences, 136, 12-23. https://doi.org/10. 1016/j.paid.2017.07.001

Cervone, D., Mercurio, L., \& Lilley, C. (2020). The individual stem student in context: Idiographic methods for understanding self-knowledge and intraindividual patterns of self-efficacy appraisal. Journal of Educational Psychology, 112, 1597-1613. https://doi.org/10.1037/edu0000454

Collins, M. D., Jackson, C. J., Walker, B. R., O'Connor, P. J., \& Gardiner, E. (2017). Integrating the context-appropriate balanced attention model and reinforcement sensitivity theory: Towards a domain-general personality process model. Psychological Bulletin, 143(1), 91-106. https://doi. org/10.1037/bul0000082

Conner, T., \& Mehl, M. R. (2015). Ambulatory assessment-Methods for studying everyday life. In R. A. Scott, S. M. Kosslyn \& M. Stephen (Eds.), Emerging trends in the social and behavioral sciences: An interdisciplinary, searchable, and linkable resource (pp. 1-15). Hoboken, NJ: Wiley. https://doi.org/10.1002/9781118900772.etrds0010

Cook, T. D., Campbell, D. T., \& Day, A. (1979). Quasi-experimentation:Design Eanalysis issuesfor field settings, Vol. 351. Boston, MA: Houghton Mifflin.

Corr, P. J. (2004). Reinforcement sensitivity theory and personality. Neuroscience \& Biobehavioral Reviews, 28, 317-332. https://doi.org/10.1016/j.neubiorev.2004.01.005

Corr, P. J. (2008). Reinforcement sensitivity theory (RST): introduction. In P. J. Corr (Ed.), The reinforcement sensitivity theory of personality (pp. 1-43). Cambridge, UK: Cambridge University Press. https://doi.org/10.1017/CBO9780511819384.002

Costantini, G., Richetin, J., Preti, E., Casini, E., Epskamp, S., \& Perugini, M. (2019). Stability and variability of personality networks. A tutorial on recent developments in network psychometrics. Personality and Individual Differences, 136, 68-78. https://doi.org/10. 1016/j.paid.2017.06.011

Cramer, A. O. J., Van Der Sluis, S., Noordhof, A., Wichers, M., Geschwind, N., Aggen, S. H., ... Borsboom, D. (2012). Dimensions of normal personality as networks in search of equilibrium: You can't like parties if you don't like people. European Journal of Personality, 26, 414-431. https://doi.org/10.1002/per.1866

Cronbach, L. J., \& Gleser, C. G. (1957). Psychological tests and personnel decisions. Urbana, IL: University of Illinois Press.

Cronbach, L. J., Gleser, G. C., Nanda, H., \& Rajaratnam, N. (1972). The dependability of behavioral measurements: Theory of generalizability for scores and profiles. New York, NY: Wiley.

Csikszentmihalyi, M., \& Larson, R. (2014). Validity and reliability of the experience-sampling method. In M. Csikszentmihalyi \& R. Larson (Eds.), Flow and the foundations of positive 
psychology (pp. 35-54). New York, NY: Springer. https://doi.org/10.1097/00005053198709000-00004

Dang, J., King, K. M., \& Inzlicht, M. (2020). Why are self-report and behavioral measures weakly correlated? Trends in Cognitive Sciences, 24, 267-269. https://doi.org/10.1016/j.tics.2020.01. 007

Danvers, A. F., Wundrack, R., \& Mehl, M. R. (2019). Equilibria in personality states: a conceptual primer for dynamical analyses. https://doi.org/10.31234/osf.io/72dvx

Dawood, S., Dowgwillo, E. A., Wu, L. Z., \& Pincus, A. L. (2018). Contemporary integrative interpersonal theory of personality. In V. Zeigler-Hill \& T. K. Shackelford (Eds.), Handbook of personality and individual differences: The science of personality and individual differences (pp. 171-202). Newbury Park, CA: Sage. https://doi.org/10.4135/9781526451163.n8

Debusscher, J., Hofmans, J., \& De Fruyt, F. (2016a). Do personality states predict momentary task performance? The moderating role of personality variability. Journal of Occupational and Organizational Psychology, 89(2), 330-351. https://doi.org/10.1111/joop.12126

Debusscher, J., Hofmans, J., \& De Fruyt, F. (2016b). From state neuroticism to momentary task performance: A person $\mathrm{x}$ situation approach. European Journal of Work and Organizational Psychology, 25(1), 89-104. https://doi.org/10.1080/1359432X.2014.983085

Debusscher, J., Hofmans, J., \& De Fruyt, F. (2017). The multiple face(t)s of state conscientiousness: Predicting task performance and organizational citizenship behavior. Journal of Research in Personality, 69, 78-85. https://doi.org/10.1016/j.jrp.2016.06.009

Debusscher, J., Hofmans, J., \& De Fruyt, F. (2014). The curvilinear relationship between state neuroticism and momentary task performance. PLoS One, 9(9), e106989. https://doi.org/10. 1371/journal.pone.0106989

Dejonckheere, E., Mestdagh, M., Houben, M., Rutten, I., Sels, L., Kuppens, P., \& Tuerlinckx, F. (2019). Complex affect dynamics add limited information to the prediction of psychological well-being. Nature Human Behaviour, 3, 478-491. https://doi.org/10.1038/s41562-019-0555-0

Denissen, J. J. A., Luhmann, M., Chung, J. M., \& Bleidorn, W. (2019). Transactions between life events and personality traits across the adult lifespan. Journal of Personality and Social Psychology, 116, 612-633. https://doi.org/10.1037/pspp0000196

DeYoung, C. G. (2013). The neuromodulator of exploration: A unifying theory of the role of dopamine in personality. Frontiers in buman neuroscience, 7, 1-26.

DeYoung, C. G. (2015). Cybernetic Big Five Theory. Journal of Research in Personality, 56, 33-58. https://doi.org/10.1016/j.jrp.2014.07.004

DeYoung, C. G., Chmielewski, M., Clark, L. A., Condon, D. M., Kotov, R., Krueger, R. F., . . Wright, A. G. C. (2020). The distinction between symptoms and traits in the Hierarchical Taxonomy of Psychopathology (HiTOP). Journal of Personality. Advance Online Publication. https://doi. org/10.1111/jopy.12593

DeYoung, C. G., \& Krueger, R. F. (2018). A cybernetic theory of psychopathology. Psychological Inquiry, 29, 117-138. https://doi.org/10.1080/1047840X.2018.1513680

Dunlop, W. L. (2017). The Narrative Identity Structure Model (NISM). Imagination, Cognition and Personality, 37, 153-177. https://doi.org/10.1177/0276236617733825

Dweck, C. S. (2017). From needs to goals and representations: Foundations for a unified theory of motivation, personality, and development. Psychological Review, 124, 689-719. https://doi. org/10.1037/rev0000082

Ebner-Priemer, U. W., \& Kubiak, T. (2007). Psychological and psychophysiological ambulatory monitoring: A review of hardware and software solutions. European Journal of Psychological Assessment, 23, 214-226. https://doi.org/10.1027/1015-5759.23.4.214

Elliott, M. L., Knodt, A. R., Ireland, D., Morris, M. L., Poulton, R., Ramrakha, S., , . Hariri, A. R. (2019). Poor test-retest reliability of task-fMRI: New empirical evidence and a meta-analysis. Biological Psychiatry, 87(9), 132-133. https://doi.org/10.1101/681700

Epskamp, S., Waldorp, L. J., Mõttus, R., \& Borsboom, D. (2018). The Gaussian graphical model in cross-sectional and time-series data. Multivariate Behavioral Research, 53, 453-480. https:// doi.org/10.1080/00273171.2018.1454823 
Fahrenberg, J., Myrtek, M., Pawlik, K., \& Perrez, M. (2007). Ambulatory assessment-Monitoring behavior in daily life settings: A behavioral-scientific challenge for psychology. European Journal of Psychological Assessment, 23, 206-213. https://doi.org/10.1027/1015-5759.23.4. 206

Fajkowska, M. (2013). Personality coherence and incoherence: A perspective on anxiety and depressed mood. Clinton Corners, NY: Eliot Werner Publications.

Fajkowska, M. (2015). The complex-system approach to personality: Main theoretical assumptions. Journal of Research in Personality, 56, 15-32. https://doi.org/10.1016/j.jrp.2014.09.003

Fayn, K., Silvia, P. J., Dejonckheere, E., Verdonck, S., \& Kuppens, P. (2019). Confused or curious? Openness/intellect predicts more positive interest-confusion relations. Journal of Personality and Social Psychology, 117, 1016-1033. https://doi.org/10.1037/pspp0000257

Fisher, C. D., Minbashian, A., Beckmann, N., \& Wood, R. E. (2013). Task appraisals, emotions, and performance goal orientation. Journal of Applied Psychology, 98, 364-373. https://doi.org/10. $1037 / \mathrm{a} 0031260$

Fleeson, W. (2001). Toward a structure-and process-integrated view of personality: Traits as density distributions of states. Journal of Personality and Social Psychology, 80, 1011-1027. https:// doi.org/10.1037/0022-3514.80.6.1011

Fleeson, W. (2007). Situation-based contingencies underlying trait-content manifestation in behavior. Journal of Personality, 75, 825-862. https://doi.org/10.1111/j.1467-6494.2007. 00458.x

Fleeson, W., \& Jayawickreme, E. (2015). Whole trait theory. Journal of Research in Personality, 56, 82-92. https://doi.org/10.1016/j.jrp.2014.10.009

Fleeson, W., \& Jayawickreme, E. (2020). Whole trait theory puts dynamics at the core of structure. In J. F. Rauthmann (Ed.), Handbook of personality dynamics and processes, 1st ed. Amsterdam, The Netherlands: Elsevier.

Fleeson, W., \& Jolley, S. (2006). A proposed theory of the adult development of intraindividual variability in trait-manifesting behavior. In D. K. Mroczek \& T. D. Little (Eds.), Handbook of personality development (pp. 41-59). Mahwah, NJ: Lawrence Erlbaum Associates Publishers. https://doi.org/10.4324/9781315805610.ch3

Forsythe, R., Horowitz, J. L., Savin, N. E., \& Sefton, M. (1994). Fairness in simple bargaining experiments. Games and Economic Behavior, 6, 347-369. https://doi.org/10.1006/game. 1994.1021

Freud, S. (1958). The dynamics of transference. In The standard edition of the complete psychological works of Sigmund Freud, Volume XII (1911-1913): The case of Schreber, papers on technique and other works (pp. 97-108). London, UK: Hogarth Press.

Funder, D. C. (2001). Personality. Annual Review of Psychology, 52(1), 197-221. https://doi.org/ 10.1146/annurev.psych.52.1.197

Furr, R. M. (2020). Variability and consistency in the analysis of behavior. In J. F. Rauthmann (Ed.), Handbook of personality dynamics and processes, 1st ed. Amsterdam, The Netherlands: Elsevier.

Gates, K. M., \& Molenaar, P. C. (2012). Group search algorithm recovers effective connectivity maps for individuals in homogeneous and heterogeneous samples. NeuroImage, 63(1), 310-319. https://doi.org/10.1016/j.neuroimage.2012.06.026

Geiser, C., Hintz, F., Burns, G., \& Servera, M. (2020a). Longitudinal structural equation modeling of personality data. In J. F. Rauthmann (Ed.), Handbook of personality dynamics and processes, 1st ed. Amsterdam, The Netherlands: Elsevier.

Geiser, C., Hintz, F., Burns, G., \& Servera, M. (2020b). Multitrait-multimethod-multioccasion modeling of personality data. In J. F. Rauthmann (Ed.), Handbook of personality dynamics and processes, 1st ed. Elsevier.

Geukes, K., Breil, S. M., Hutteman, R., Nestler, S., Küfner, A. C. P., \& Back, M. D. (2019). Explaining the longitudinal interplay of personality and social relationships in the laboratory and in the field: The PILS and the CONNECT study. PLoS One, 14(1), e0210424. https://doi.org/10.1371/journa 1.pone. 0210424 
Geukes, K., van Zalk, M. H. W., \& Back, M. D. (2017). Analyzing processes in personality development. In J. Specht (Ed.), Personality development across the lifespan (pp. 455-472). San Diego, CA: Elsevier Academic Press. https://doi.org/10.1016/B978-0-12-804674-6.00028-4

Geukes, K., van Zalk, M., \& Back, M. D. (2018). Understanding personality development: An integrative state process model. International Journal of Bebavioral Development, 42(1), 4351. https://doi.org/10.1177/0165025416677847

Grapsas, S., Brummelman, E., Back, M. D., \& Denissen, J. J. (2020). The "why" and "how" of narcissism: A process model of narcissistic status pursuit. Perspectives on Psychological Science, 15(1), 150-172. https://doi.org/10.1177/1745691619873350

Gray, J. A. (1982). The neuropsychology of anxiety: An enquiry into the functions of the septobippocampal system. Oxford, UK: Oxford University Press.

Gray, J. A., \& McNaughton, N. (2000). The neuropsychology of anxiety: An inquiry into the functions of the septo-hippocampal system. Oxford, UK: Oxford University Press.

Halvorson, M. A., Pedersen, S. L., Feil, M. C., Lengua, L. J., Molina, B. S. G., \& King, K. M. (2020). Impulsive states and impulsive traits: a study of the multilevel structure and validity of a multifaceted measure of impulsive states. Assessment. https://doi.org/10.31219/osf.io/nyevc

Hamaker, E. L., \& Wichers, M. (2017). No Time Like the Present. Current Directions in Psychological Science, 26(1), 10-15. https://doi.org/10.1177/0963721416666518

Harari, G. M., Müller, S. R., Aung, M. S. H., \& Rentfrow, P. J. (2017). Smartphone sensing methods for studying behavior in everyday life. Current Opinion in Bebavioral Sciences, 18, 83-90. https:// doi.org/10.1016/j.cobeha.2017.07.018

Harari, G. M., Müller, S. R., \& Gosling, S. D. (2018). Naturalistic assessment of situations using mobile sensing methods. In J. F. Rauthmann, R. A. Sherman \& D. C. Funder (Eds.), The Oxford bandbook of psychological situations, (pp. 299-311). Oxford, UK: Oxford University Press. https://doi. org/10.1093/oxfordhb/9780190263348.013.14

Harari, G. M., Müller, S. R., Stachl, C., Wang, R., Wang, W., Bühner, M., .. Gosling, S. D. (2020). Sensing sociability: Individual differences in young adults' conversation, calling, texting, and app use behaviors in daily life. Journal of Personality and Social Psychology, 119(1), $204-228$. https://doi.org/10.1037/pspp0000245

Heck, R. H., \& Thomas, S. L. (2015). An introduction to multilevel modeling techniques: MLM and SEM approaches using Mplus. New York, UK: Routledge. https://doi.org/10.4324/ 9781315746494

Heller, D., Perunovic, W. Q. E., \& Reichman, D. (2009). The future of person-situation integration in the interface between traits and goals: A bottom-up framework. Journal of Research in Personality, 43, 171-178. https://doi.org/10.1016/j.jrp.2008.12.011

Hopwood, C. J., \& Back, M. (2018). Interpersonal dynamics in personality and personality disorders. European Journal of Personality, 32, 499-524. https://doi.org/10.1002/per.2155

Hopwood, C. J., \& Bleidorn, W. (2018). Stability and change in personality and personality disorders. Current Opinion in Psychology, 21, 6-10. https://doi.org/10.1016/j.copsyc.2017.08.034

Hopwood, C. J., Morey, L. C., Donnellan, M. B., Samuel, D. B., Grilo, C. M., McGlashan, T. H., .. . Skodol, A. E. (2013). Ten-year rank-order stability of personality traits and disorders in a clinical sample. Journal of Personality, 81, 335-344. https://doi.org/10.1111/j.1467-6494.2012. $00801 . \mathrm{x}$

Hopwood, C. J., Zimmermann, J., Pincus, A. L., \& Krueger, R. F. (2015). Connecting personality structure and dynamics: Towards a more evidence-based and clinically useful diagnostic scheme.Journal of Personality Disorders, 29, 431-448. https://doi.org/10.1521/pedi.2015.29. 4.431

Horstmann, K. T. (2020). Experience sampling and daily diary studies: Basic concepts, designs, and challenges. In J. F. Rauthmann (Ed.), Handbook of personality dynamics and processes, 1 st ed. Elsevier.

Horstmann, K. T., Rauthmann, J. F., \& Sherman, R. A. (2018). Measurement of situational influences. In V. Zeigler-Hill \& T. K. Shackelford (Eds.), The SAGE handbook of personality and individual 
differences: The science of personality and individual differences (pp. 465-484). Newbury Park, CA: Sage. https://doi.org/10.4135/9781526451163.n21

Horstmann, K. T., Rauthmann, J. F., Sherman, R. A., \& Ziegler, M. (2020) Unveiling an exclusive link: predicting behavior with personality, situation perception, and affect in a pre-registered experience sampling study. https://doi.org/10.31234/osf.io/ztw2n

Horstmann, K. T., Ziegler, J., \& Ziegler, M. (2018). Assessment of situational perceptions. In J. F. Rauthmann, R. A. Sherman \& D. C. Funder (Eds.), The Oxford handbook of psychological situations, (pp. 343-359). Oxford, UK: Oxford University Press. https://doi.org/10.1093/oxf ordhb/9780190263348.013.21

Horstmann, K. T., \& Ziegler, M. (2020). Assessing personality states: what to consider when constructing personality state measures. European Journal of Personality, 1037-1059. https:// doi.org/10.1002/per.2266

Hox, J. J., M. Moerbeek, \& R. van de Schoot (Eds.) (2010). Multilevel analysis: Techniques and applications. New York, UK: Routledge. https://doi.org/10.4324/9781315650982

Hudson, N. W. (2020). Dynamics and processes in personality change interventions. In J. F. Rauthmann (Ed.), Handbook of personality dynamics and processes, 1st ed. Amsterdam, The Netherlands: Elsevier.

Hyatt, C. S., Weiss, B. M., Carter, N. T., Zeichner, A., \& Miller, J. D. (2018). The relation between narcissism and laboratory aggression is not contingent on environmental cues of competition. Personality Disorders: Theory, Research, and Treatment, 9, 543-552. https://doi.org/10.1037/ per0000284

Ilies, R., \& Judge, T. A. (2002). Understanding the dynamic relationships among personality, mood, and job satisfaction: A field experience sampling study. Organizational Behavior and Human Decision Processes, 89, 1119-1139. https://doi.org/10.1016/S0749-5978(02)00018-3

Jach, H. K., Smillie, L. D., \& Fajkowska, M. (2020). Testing the information-seeking theory of openness/intellect. European Journal of Personality. Advance online publication. https://doi. org/10.1002/per.2271

Jacobson, N. C., \& Chung, Y. J. (2020). Passive sensing of prediction of moment-to-moment depressed mood among undergraduates with clinical levels of depression sample using smartphones. Sensors, 20, 3572.

Jahng, S., Wood, P. K., \& Trull, T. J. (2008). Analysis of affective instability in ecological momentary assessment: Indices using successive difference and group comparison via multilevel modeling. Psychological Methods, 13, 354-375. https://doi.org/10.1037/a0014173

Jones, A. B., Brown, N. A., Serfass, D. G., \& Sherman, R. A. (2017). Personality and density distributions of behavior, emotions, and situations. Journal of Research in Personality, 69, 225-236.

Judd, C. M., Westfall, J., \& Kenny, D. A. (2012). Treating stimuli as a random factor in social psychology: A new and comprehensive solution to a pervasive but largely ignored problem. Journal of Personality and Social Psychology, 103(1), 54-69. https://doi.org/10.1037/ a0028347

Judge, T. A., Simon, L. S., Hurst, C., \& Kelley, K. (2014). What I experienced yesterday is who I am today: Relationship of work motivations and behaviors to within-individual variation in the fivefactor model of personality. Journal of Applied Psychology, 99, 199-221. https://doi.org/10. 1037/a0034485

Kahneman, D., Krueger, A. B., Schkade, D. A., Schwarz, N., \& Stone, A. A. (2004). A survey method for characterizing daily life experience: The day reconstruction method. Science, 306, 17761780. https://doi.org/10.1126/science. 1103572

Kanfer, F. H., \& Saslow, G. (1969). Behavioral diagnosis. In C. M. Franks (Ed.), Behavior therapy: Appraisal and status (pp. 417-444). New York, NY: McGraw-Hill.

Kelly, G. A. (1955). The psychology of personal constructs. Vol. 1. A theory of personality. Vol. 2. Clinical diagnosis and psychotherapy. New York, NY: W. W. Norton.

Kline, R. B. (2016). Methodology in the social sciences. Principles and practice of structural equation modeling, 4th ed. New York, NY: Guilford Press. 
Kritzler, S., Krasko, J., \& Luhmann, M. (2020). Inside the happy personality: Personality states, situation experience, and state affect mediate the relation between personality and affect. Journal of Research in Personality, 85, 103929. https://doi.org/10.1016/j.jrp.2020.103929

Kroencke, L., Geukes, K., Utesch, T., Kuper, N., \& Back, M. D. (2020). Neuroticism and emotional risk during the COVID-19 pandemic. Journal of Research in Personality, 89, 104038. https:// doi.org/10.1016/j.jrp.2020.104038

Kuhl, J. (2000). A functional-design approach to motivation and self-regulation: The dynamics of personality systems and interactions. In M. Boekaerts, P. R. Pintrich \& M. Zeidner (Eds.), Handbook of self-regulation (pp. 111-169). San Diego, CA: Academic Press. https://doi.org/10. 1016/B978-012109890-2/50034-2

Kuhl, J., Quirin, M., \& Koole, S. (2020). The functional architecture of human motivation: personality systems interactions theory. In A. J. Elliot (Ed.), Advances in motivation science (Vol. 7). Amsterdam, The Netherlands: Elsevier (in press).

Lafit, G., Adolf, J., Dejonckheere, E., Myin-Germeys, I., Viechtbauer, W., \& Ceulemans, E.. (2020). Selection of the Number of Participants in Intensive Longitudinal Studies: A User-friendly Shiny App and Tutorial to Perform Power Analysis in Multilevel Regression Models that Account for Temporal Dependencies. https://doi.org/10.31234/osf.io/dq6ky

Lewin, K. (1935). A dynamic theory of personality. New York, NY: McGraw-Hill.

Lewin, K. (1936). Principles of topological psychology. New York, NY: McGraw-Hill.

Lewin, K. (1951). Field theory in social science: selected theoretical papers (Edited by Dorwin Cartwright.). Harpers.

Li, W.-D., Li, S., Feng, J. J., Wang, M. O., Zhang, H., Frese, M., \& Wu, C.-H. (2020). Can becoming a leader change your personality? An investigation with two longitudinal studies from a role-based perspective. Journal of Applied Psychology. Advance Online Publication. https://doi.org/10. 1037/ap10000808

Lievens, F., \& Johnson, W. (2017). Assessing personality-situation interplay in personnel selection: Toward more integration into personality research. European Journal of Personality, 31, 424440. https://doi.org/10.1002/per.2111

Lievens, F., Lang, J. W. B., De Fruyt, F., Corstjens, J., Van de Vijver, M., \& Bledow, R. (2018). The predictive power of people's intraindividual variability across situations: Implementing whole trait theory in assessment. Journal of Applied Psychology, 103, 753-771. https://doi.org/10. 1037/ap10000280

Lilgendahl, J. P., \& McLean, K. C. (2019). Narrative identity processes and patterns of adjustment across the transition to college: A developmentally contextualized approach. Journal of Personality and Social Psychology, 119, 960-977. Advance Online Publication. https://doi.org/ $10.1037 /$ pspp0000277

Liu, S., Kuppens, P., \& Bringmann, L. (2019). On the use of empirical bayes estimates as measures of individual traits. Assessment. Advance Online Publication. https://doi.org/10.1177/ 1073191119885019

Lombardo, G. P., \& Foschi, R. (2003). The concept of personality in 19th-century French and 20thcentury American psychology. History of Psychology, 6, 123-142. https://doi.org/10.1037/ 1093-4510.6.2.123

Lucas, R. E., Wallsworth, C., Anusic, I., \& Donnellan, M. B. (2020). A direct comparison of the day reconstruction method (DRM) and the experience sampling method (ESM). Journal of Personality and Social Psychology. Advance Online Publication. https://doi.org/10.1037/ pspp0000289

Luhmann, M., Orth, U., Specht, J., Kandler, C., \& Lucas, R. E. (2014). Studying changes in life circumstances and personality: It's about time. European Journal of Personality, 28, 256-266. https://doi.org/10.1002/per.1951

MacCoon, D. G., Wallace, J. F., \& Newman, J. P. (2004). Self-Regulation: The context-appropriate allocation of attentional capacity to dominant and nondominant cues. In R. F. Baumeister \& K. D. Vohs (Eds.), Handbook of self-regulation research (pp. 422-444). New York, NY: Guilford Press. 
Mackie, J. L. (1965). Causes and Conditions. American Philosophical Quarterly, 2, 245-264.

Markus, H., \& Wurf, E. (1987). The dynamic self-concept: A social psychological perspective. Annual Review of Psychology, 38, 299-337. https://doi.org/10.1146/annurev.ps.38.020187. 001503

Mayer, J. D. (2015). The personality systems framework: Current theory and development. Journal of Research in Personality, 56, 4-14. https://doi.org/10.1016/j.jrp.2015.01.001

McAdams, D. P. (2013). The psychological self as actor, agent, and author. Perspectives on Psychological Science, 8, 272-295. https://doi.org/10.1177/1745691612464657

McAdams, D. P., \& McLean, K. C. (2013). Narrative identity. Current Directions in Psychological Science, 22, 233-238. https://doi.org/10.1177/0963721413475622

McAdams, D. P., \& Pals, J. L. (2006). A new Big Five: fundamental principles for an integrative science of personality. American Psychologist, 61, 204. https://doi.org/10.1037/0003-066X.61.3.204

McLean, K. C., Pasupathi, M., \& Pals, J. L. (2007). Selves creating stories creating selves: A process model of self-development. Personality and Social Psychology Review, 11, 262-278. https:// doi.org/10.1177/1088868307301034

Mehl, M. R. (2017). The electronically activated recorder (EAR) a method for the naturalistic observation of daily social behavior. Current Directions in Psychological Science, 26, 184-190. https://doi.org/10.1177/0963721416680611

Mehta, Y., Majumder, N., Gelbukh, A., \& Cambria, E. (2019). Recent trends in deep learning based personality detection. Artificial Intelligence Review, 53, 2313-2339. https://doi.org/10.1007/ s10462-019-09770-z

Minbashian, A., Wood, R. E., \& Beckmann, N. (2010). Task-contingent conscientiousness as a unit of personality at work. Journal of Applied Psychology, 95, 793-806. https://doi.org/10.1037/ a0020016

Mischel, W., \& Morf, C. C. (2003). The self as a psycho-social dynamic processing system: A metaperspective on a century of the self in psychology. In M. R. Leary \& J. P. Tangney (Eds.), Handbook of self and identity (pp. 15-43). New York, NY: Guilford Press.

Mischel, W., \& Shoda, Y. (1995). A cognitive-affective system theory of personality: reconceptualizing situations, dispositions, dynamics, and invariance in personality structure. Psychological Review, 102, 246-268.

Molenaar, P. C. (1985). A dynamic factor model for the analysis of multivariate time series. Psychometrika, 50, 181-202.

Molenaar, P. C. (2004). A manifesto on psychology as idiographic science: Bringing the person back into scientific psychology, this time forever. Measurement, 2, 201-218. https://doi.org/10. 1207/s15366359mea0204_1

Molenaar, P. C. M., \& Nesselroade, J. R. (2009). The recoverability of P-technique factor analysis. Multivariate Behavioral Research, 44(1), 130-141. https://doi.org/10.1080/ 00273170802620204

Montag, C., \& Elhai, J. D. (2019). A new agenda for personality psychology in the digital age? Personality and Individual Differences, 147, 128-134. https://doi.org/10.1016/j.paid.2019. 03.045

Morf, C. C. (2006). Personality Reflected in a Coherent Idiosyncratic Interplay of Intra- and Interpersonal Self-Regulatory Processes. Journal of Personality, 74, 1527-1556. https://doi. org/10.1111/j.1467-6494.2006.00419.x

Morin, A. (2017). Toward a glossary of self-related terms. Frontiers in Psychology, 8, 280. https:// doi.org/10.3389/fpsyg.2017.00280

Morin, A., \& Racy, F. (2020). Dynamic self-processes. In J. F. Rauthmann (Ed.), Handbook of personality dynamics and processes, 1 st ed. Amsterdam, The Netherlands: Elsevier.

Mõttus, R., Allerhand, M., \& Johnson, W. (2017). Computational modeling of person-situation transactions transactions: How accumulation of situational experiences can shape the distributions of trait scores. In J. F. Rauthmann, R. A. Sherman \& D. C. Funder (Eds.), The Oxford handbook of psychological situations (pp. 255-268). Oxford, UK: Oxford University Press. https://doi.org/10.1093/oxfordhb/9780190263348.013.23 
Müller, S. R. (2019). Understanding the relationship between people and their environments using smartphone data: A Study of Personality, Places Visited, and Emotional Experiences (Doctoral thesis). https://doi.org/10.17863/CAM.39027

Muthén, B. O. (1994). Multilevel covariance structure analysis. Sociological Methods \& Research, 22, 376-398. https://doi.org/10.1177/0049124194022003006

Neisser, U. (1967). Cognitive psychology. New York, NY: Appleton-Century-Crofts.

Neubauer, A. B., Voelkle, M. C., Voss, A., \& Mertens, U. K. (2020). Estimating reliability of withinperson couplings in a multilevel framework. Journal of Personality Assessment, 102(1), 10-21. https://doi.org/10.1080/00223891.2018.1521418

Nezlek, J. B. (2008). An introduction to multilevel modeling for social and personality psychology. Social and Personality Psychology Compass, 2, 842-860. https://doi.org/10.1111/j.1751-9004. 2007.00059.x

Noftle, E. E., \& Fleeson, W. (2015). Intraindividual variability in adult personality development. In M. Diehl, K. Hooker \& M. J. Sliwinski (Eds.), Handbook of intraindividual variability across the life span (pp. 176-197). New York, NY: Routledge/Taylor \& Francis Group.

Oravecz, Z., Tuerlinckx, F., \& Vandekerckhove, J. (2011). A hierarchical latent stochastic differential equation model for affective dynamics. Psychological Methods, 16, 468-490. https://doi.org/ $10.1037 / \mathrm{a} 0024375$

Oravecz, Z., Tuerlinckx, F., \& Vandekerckhove, J. (2016). Bayesian data analysis with the bivariate hierarchical Ornstein-Uhlenbeck process model. Multivariate Behavioral Research, 51(1), 106-119. https://doi.org/10.1080/00273171.2015.1110512

Pals, J. L. (2006). Narrative identity processing of difficult life experiences: pathways of personality development and positive self-transformation in adulthood. Journal of Personality, 74, 10791110. https://doi.org/10.1111/j.1467-6494.2006.00403.x

Patterson, C. M., \& Newman, J. P. (1993). Reflectivity and learning from aversive events: Toward a psychological mechanism for the syndromes of disinhibition. Psychological Review, 100, 716736. https://doi.org/10.1037/0033-295X.100.4.716

Pincus, A. L. (2005). A contemporary integrative interpersonal theory of personality disorders. In M. F. Lenzenweger \& J. F. Clarkin (Eds.), Major theories of personality disorder (pp. 282-331). New York, NY: Guilford Press.

Pincus, A. L., \& Ansell, E. B. (2013). Interpersonal theory of personality. In H. Tennen, J. Suls \& I. B. Weiner (Eds.), Handbook of psychology: Personality and social psychology (pp. 141-159). New York, NY: John Wiley \& Sons Inc.

Pincus, A. L., \& Hopwood, C. F. (2012). A contemporary interpersonal model of personality pathology and personality disorder. In T. A. Widiger (Ed.), Oxford library of psychology. The Oxford handbook of personality disorders (pp. 372-398). Oxford, UK: Oxford University Press. https://doi.org/10.1093/oxfordhb/9780199735013.013.0018

Preacher, K. J., Zyphur, M. J., \& Zhang, Z. (2010). A general multilevel SEM framework for assessing multilevel mediation. Psychological Methods, 15(3), 209-233. https://doi.org/10.1037/ a0020141

Quintus, M., Egloff, B., \& Wrzus, C. (2020). Daily life processes predict long-term development in explicit and implicit representations of Big Five traits: Testing predictions from the TESSERA (Triggering situations, Expectancies. States and State Expressions, and ReActions) Framework. Journal of Personality and Social Psychology. Advance Online Publication. https://doi.org/10. 1037/pspp0000361

Quirin, M., Robinson, M. D., Rauthmann, J. F., Kuhl, J., Read, S. J., Tops, M., . . Epskamp, S. (2020). Uncovering the causal mechanisms of personality: the personality dynamics approach. European Journal of Personality. Advance Online Publication. https://doi.org/10.1002/per.2295

Rabe-Hesketh, S., Skrondal, A., \& Pickles, A. (2004). Generalized multilevel structural equation modeling. Psychometrika, 69, 167-190. https://doi.org/10.1007/BF02295939

Raudenbush, S. W., \& Bryk, A. S. (2002). Hierarchical linear models: Applications and data analysis methods. Thousand Oaks, CA: Sage. 
Rauthmann, J. F. (2015). Structuring situational information. European Psychologist, 20, 176-189. https://doi.org/10.1027/1016-9040/a000225

Rauthmann, J. F. (2017). What are other-rated scales composed of? Sources of measurement error and true trait variance in other-ratings of the Big Five. Journal of Research in Personality, 70 , 45-55. https://doi.org/10.1016/j.jrp.2017.05.002

Rauthmann, J. F. (2020a). Capturing interactions, correlations, fits, and transactions: a personenvironment relations model. In J. F. Rauthmann (Ed.), Handbook of personality dynamics and processes, 1st ed. Amsterdam, The Netherlands: Elsevier.

Rauthmann, J. F. (2020b). Handbook of personality dynamics and processes, 1st ed. Amsterdam, The Netherlands: Elsevier.

Rauthmann, J. F., Horstmann, K. T., \& Sherman, R. A. (2020). The psychological characteristics of situations: towards an integrated taxonomy. In J. F. Rauthmann, R. A. Sherman \& D. C. Funder (Eds.), The oxford handbook of psychological situations (pp. 389-404). Oxford, UK: Oxford University Press.

Rauthmann, J. F., Jones, A. B., \& Sherman, R. A. (2016). Directionality of person-situation transactions: Are there spillovers among and between situation experiences and personality states? Personality and Social Psychology Bulletin, 42(7), 893-909. https://doi.org/10.1177/ 0146167216647360

Rauthmann, J. F., \& Sherman, R. A. (2020). The situation of situation research: knowns and unknowns. Current Directions in Psychological Science, 29(5), 473-480. https://doi.org/10. $1177 / 0963721420925546$

Rauthmann, J. F., Sherman, R. A., \& Funder, D. C. (2015). Principles of situation research: Towards a better understanding of psychological situations. European Journal of Personality, 29, 363381. https://doi.org/10.1002/per.1994

Read, S. J., Brown, A. D., Wang, P., \& Miller, L. C. (2020). Neural networks and virtual personalities: Capturing the structure and dynamics of personality. In J. F. Rauthmann (Ed.), Handbook of personality dynamics and processes, 1st ed. Amsterdam, The Netherlands: Elsevier.

Read, S. J., \& Miller, L. C. (2002). Virtual personalities: A neural network model of personality. Personality and Social Psychology Review, 6, 357-369. https://doi.org/10.1207/ S15327957PSPR0604_10

Read, S. J., Monroe, B. M., Brownstein, A. L., Yang, Y., Chopra, G., \& Miller, L. C. (2010). A neural network model of the structure and dynamics of human personality. Psychological Review, 117 (1), 61-92. https://doi.org/10.1037/a0018131

Read, S. J., Smith, B. J., Droutman, V., \& Miller, L. C. (2017). Virtual personalities: Using computational modeling to understand within-person variability. Journal of Research in Personality, 69, 237-249. https://doi.org/10.1016/j.jrp.2016.10.005

Revelle, W. (2007). Experimental approaches to the study of personality. In R. W. Robins, R. C. Fraley \& R. F. Krueger (Eds.), Handbook of research methods in personality psychology (pp. 37-61). New York, NY: The Guilford Press.

Revelle, W., \& Condon, D. M. (2015). A model for personality at three levels. Journal of Research in Personality, 56, 70-81. https://doi.org/10.1016/j.jrp.2014.12.006

Revelle, W., \& Wilt, J. (2020). The Dynamics of Personality. In J. F. Rauthmann (Ed.), Handbook of personality dynamics and processes, 1 st ed. Amsterdam, The Netherlands: Elsevier.

Ringwald, W. R., Hallquist, M., Dombrovski, A., \& Wright, A. G. (2020). Transdiagnostic predictors of interpersonal and affective variability in borderline personality pathology. https://doi.org/10. 31234/osf.io/sh7cz

Ringwald, W. R., Woods, W. C., Edershile, E. A., Sharpe, B. M., \& Wright, A. G. (2020). Psychopathology and personality functioning. In J. F. Rauthmann (Ed.), Handbook of personality dynamics and processes, 1st ed. Amsterdam, The Netherlands: Elsevier.

Roberts, B. W. (2018). A revised sociogenomic model of personality traits. Journal of Personality, 86(1), 23-35. https://doi.org/10.1111/jopy.12323 
Roberts, B. W., \& DelVecchio, W. F. (2000). The rank-order consistency of personality traits from childhood to old age: A quantitative review of longitudinal studies. Psychological Bulletin, 126 (1), 3-25. https://doi.org/10.1037/0033-2909.126.1.3

Roberts, B. W., \& Jackson, J. J. (2008). Sociogenomic personality psychology. Journal of Personality, 76, 1523-1544. https://doi.org/10.1111/j.1467-6494.2008.00530.x

Roberts, B. W., \& Nickel, L. B. (2017). A critical evaluation of the Neo-Socioanalytic Model of personality. In J. Specht (Ed.), Personality development across the lifespan (pp. 157-177). San Diego, CA: Elsevier Academic Press. https://doi.org/10.1016/B978-0-12-804674-6.00011-9

Roberts, B. W., Walton, K. E., \& Viechtbauer, W. (2006). Patterns of mean-level change in personality traits across the life course: A meta-analysis of longitudinal studies. Psychological Bulletin, 132 (1), 1-25. https://doi.org/10.1037/0033-2909.132.1.1

Roberts, B. W., \& Wood, D. (2006). Personality development in the context of the neo-socioanalytic model of personality. In D. K. Mroczek \& T. D. Little (Eds.), Handbook of personality development (pp. 11-39). Mahwah, NJ: Lawrence Erlbaum Associates Publishers.

Robinaugh, D., Haslbeck, J. M. B., Ryan, O., Fried, E. I., \& Waldorp, L. (2020). Invisible hands and fine calipers: a call to use formal theory as a toolkit for theory construction. https://doi.org/10. 31234/osf.io/ugz7y

Rogers, C. R. (1959). A theory of therapy, personality, and interpersonal relationships, as developed in the client-centered framework. In S. Koch (Ed.), Psychology: A study of a science, Vol. 3 (pp. 184-256). New York, NY: McGraw-Hill.

Russell, J. A. (2003). Core affect and the psychological construction of emotion. Psychological Review, 110(1), 145-172. https://doi.org/10.1037/0033-295X.110.1.145

Sadikaj, G., Wright, A. G., Dunkley, D., Zuroff, D., \& Moskowitz, D. S. (2020). Multilevel structural equation modeling for intensive longitudinal data: A practical guide for personality researchers. In J. F. Rauthmann (Ed.), Handbook of personality dynamics and processes, 1st ed. Amsterdam, The Netherlands: Elsevier.

Scherbaum, C. A., \& Pesner, E. (2019). Power analysis for multilevel research. In S. E. Humphrey \& J. M. LeBreton (Eds.), The handbook of multilevel theory, measurement, and analysis (pp. 329352). Washington, DC: American Psychological Association. https://doi.org/10.1037/0000115015

Scherpenzeel, A. (2011). Data collection in a probability-based internet panel: how the LISS panel was built and how it can be used. Bulletin of Sociological Methodology/Bulletin De Méthodologie Sociologique, 109(1), 56-61. https://doi.org/10.1177/0759106310387713

Schimmack, U. (2003). Affect measurement in Experience Sampling research.Journal of Happiness Studies: an Interdisciplinary Forum on Subjective Well-Being, 4(1), 79-106. https://doi.org/ 10.1023/A:1023661322862

Schmitt, M. (2009). Person $\mathrm{x}$ situation - interactions as moderators. Journal of Research in Personality, 43, 267. http://doi.org/10.1016/j.jrp.2008.12.032

Sharpe, B. M., Simms, L. J., \& Wright, A. G. (2020). Impulsivity, affect, and stress in daily life: Examining a cascade model of urgency. Journal of Personality Disorders, 1-19. Advance Online Publication. https://doi.org/10.1521/pedi_2020_34_465

Sherman, R. A., Rauthmann, J. F., Brown, N. A., Serfass, D. G., \& Jones, A. B. (2015). The independent effects of personality and situations on real-time expressions of behavior and emotion. Journal of Personality and Social Psychology, 109, 872-888. https://doi.org/10.1037/pspp0000036

Shiffman, S., Stone, A. A., \& Hufford, M. R. (2008). Ecological Momentary Assessment. Annual Review of Clinical Psychology, 4(1), 1-32. https://doi.org/10.1146/annurev.clinpsy.3.022806. 091415

Silvia, P. J., Kwapil, T. R., Walsh, M. A., \& Myin-Germeys, I. (2014). Planned missing-data designs in experience-sampling research: Monte Carlo simulations of efficient designs for assessing withinperson constructs. Behavior Research Methods, 46(1), 41-54. https://doi.org/10.3758/s13428013-0353-y 
Simons, D. J., Shoda, Y., \& Lindsay, D. S. (2017). Constraints on generality (COG): A proposed addition to all empirical papers. Perspectives on Psychological Science, 12, 1123-1128. https:// doi.org/10.1177/1745691617708630

Sosnowska, J., Hofmans, J., \& De Fruyt, F. (2019a). Relating neuroticism to emotional exhaustion: A dynamic approach to personality. Frontiers in Psychology, 10, 2264. https://doi.org/10.3389/ fpsyg.2019.02264

Sosnowska, J., Hofmans, J., \& De Fruyt, F. (2019b). Revisiting the neuroticism-performance link: A dynamic approach to individual differences. Journal of Occupational and Organizational Psychology, 93, 495-504. https://doi.org/10.1111/joop.12298

Sosnowska, J., Hofmans, J., \& Lievens, F. (2020). Assessing personality dynamics in personnel selection. In J. F. Rauthmann (Ed.), Handbook of personality dynamics and processes, 1 st ed. Amsterdam, The Netherlands: Elsevier.

Sosnowska, J., Kuppens, P., De Fruyt, F., \& Hofmans, J. (2019). A dynamic systems approach to personality: The Personality Dynamics (PersDyn) model. Personality and Individual Differences, 144, 11-18. https://doi.org/10.1016/j.paid.2019.02.013

Sosnowska, J., Kuppens, P., De Fruyt, F., \& Hofmans, J. (2020). New directions in the conceptualization and assessment of personality-a dynamic systems approach. European Journal of Personality, 34, 988-998. https://doi.org/10.1002/per.2233

Stachl, C., Au, Q., Schoedel, R., Buschek, D., Völkel, S., Schuwerk, T., ...Bühner, M. (2019). Behavioral patterns in smartphone usage predict big five personality traits. https://doi.org/10. 1073/pnas.1920484117

Strack, F., \& Deutsch, R. (2004). Reflective and impulsive determinants of social behavior. Personality and Social Psychology Review, 8, 220-247. https://doi.org/10.1207/ s15327957pspr0803_1

Taylor, M. F., Brice, J., Buck, N., \& Prentice-Lane, E. (1993). British household panel survey user manual: Volume A: Introduction, technical report and appendices. Colchester: University of Essex.

Tett, R. P., \& Guterman, H. A. (2000). Situation trait relevance, trait expression, and cross-situational consistency: Testing a principle of trait activation. Journal of Research in Personality, 34, 397423. https://doi.org/10.1006/jrpe.2000.2292

Tett, R. P., Simonet, D. V., Walser, B., \& Brown, C. (2013). Trait activation theory: Applications, developments, and implications for person-workplace fit. In N. D. Christiansen \& R. P. Tett (Eds.), Handbook of personality at work (pp. 71-100). New York, NY: Routledge.

Thapa, S., Beck, E. D., \& Tay, L. (2020). Personality affect construal theory: a model of personality and affect in the workplace. In L. Q. Yang, R. Cropanzano, C. S. Daus \& V. Martínez-Tur (Eds.), The cambridge handbook of workplace affect (pp. 37-51). Cambridge, UK: Cambridge University Press. https://doi.org/10.1017/9781108573887.004

Uher, J. (2016). What is behaviour? And (when) is language behaviour? A metatheoretical definition. Journal for the Theory of Social Behaviour, 46, 475-501. https://doi.org/10.1111/jtsb.12104

Uher, J. (2017). Basic definitions in personality psychology: Challenges for conceptual integrations. European Journal of Personality, 31, 572-573. https://doi.org/10.1002/per.2128

Usami, S., Murayama, K., \& Hamaker, E. L. (2019). A unified framework of longitudinal models to examine reciprocal relations. Psychological Methods, 24, 637-657. https://doi.org/10.1037/me t0000210

Van Egeren, L. F. (2009). A cybernetic model of global personality traits. Personality and Social Psychology Review, 13, 92-108. https://doi.org/10.1177/1088868309334860

van Halem, S., Van Roekel, E., Kroencke, L., Kuper, N., \& Denissen, J. (2020). Moments that matter? On the complexity of using triggers based on skin conductance to sample arousing events within an experience sampling framework. European Journal of Personality, 34, 794-807. https:// doi.org/10.1002/per.2252

Voelkle, M. C., Oud, J. H. L., Davidov, E., \& Schmidt, P. (2012). An SEM approach to continuous time modeling of panel data: Relating authoritarianism and anomia. Psychological Methods, 17, 176192. https://doi.org/10.1037/a0027543 
Vogelsmeier, L. V. D. E., Vermunt, J. K., van Roekel, E., \& De Roover, K. (2019). Latent markov factor analysis for exploring measurement model changes in time-intensive longitudinal studies. Structural Equation Modeling, 26, 557-575. https://doi.org/10.1080/10705511.2018. 1554445

Wagner, G., Frick, J., \& Schupp, J. (2007). The German Socio- Economic Panel Study (SOEP): Scope, evolution and enhancements (SOEPpapers on Multidisciplinary Panel Data Research No. 1). DIW Berlin, The German Socio-Economic Panel (SOEP). Retrieved from http://econpapers.re pec.org/paper/diwdiwsop/diw_5fsp1.htm

Warner, R. M., Kenny, D. A., \& Stoto, M. (1979). A new round robin analysis of variance for social interaction data.Journal of Personality and Social Psychology, 37, 1742-1757. https://doi.org/ 10.1037/0022-3514.37.10.1742

Wendt, L. P., Wright, A. G. C., Pilkonis, P. A., Woods, W. C., Denissen, J., Kuhnel, A., \& Zimmerman, J. (2020). Indicators of affect dynamics: Structure, test-retest reliability, and personality correlates. European Journal of Personality. Advance Online Publication. https://doi.org/10. 1002/per.2277

Wessels, N. M., Zimmermann, J., \& Leising, D. (2016). Toward a shared understanding of important consequences of personality. Review of General Psychology, 20, 426-436. https://doi.org/10. 1037/gpro000088

Wiernik, B. M., Ones, D. S., Marlin, B. M., Giordano, C., Dilchert, S., Mercado, B. K., . . Al'Absi, M. (2020). Using mobile sensors to study personality dynamics. European Journal of Psychological Assessment. Advance Online Publication. https://doi.org/10.1027/1015-5759/ a000576

Wille, B., \& De Fruyt, F. (2014). Vocations as a source of identity: Reciprocal relations between Big Five personality traits and RIASEC characteristics over 15 years. Journal of Applied Psychology, 99, 262-281. http://doi.org/10.1037/a0034917

Wilt, J., \& Revelle, W. (2015). Affect, behaviour, cognition and desire in the big five: An analysis of item content and structure. European Journal of Personality, 29, 478-497. https://doi.org/10. 1002/per.2002

Wood, D., Gardner, M. H., \& Harms, P. D. (2015). How functionalist and process approaches to behavior can explain trait covariation. Psychological Review, 122, 84-111. https://doi.org/10. 1037/a0038423

Wood, D., Spain, S. M., \& Harms, P. D. (2017). Functional approaches to representing the interplay of situations, persons, and behavior. In J. F. Rauthmann, R. A. Sherman \& D. C. Funder (Eds.), The Oxford handbook of psychological situations. Oxford, UK: Oxford University Press. https:// doi.org/10.1093/oxfordhb/9780190263348.013.25

Wood, D., Spain, S. M., Monroe, B., \& Harms, P. D. (2020). Using functional fields to represent accounts of the psychological processes that produce actions. In J. F. Rauthmann (Ed.), Handbook of personality dynamics and processes. Amsterdam, The Netherlands: Elsevier.

Wood, R. E., Beckmann, N., Birney, D. P., Beckmann, J. F., Minbashian, A., \& Chau, R. (2019). Situation contingent units of personality at work. Personality and Individual Differences, 136, 113-121. https://doi.org/10.1016/j.paid.2018.01.026

Wright, A. G. C., Gates, K. M., Arizmendi, C., Lane, S. T., Woods, W. C., \& Edershile, E. A. (2019). Focusing personality assessment on the person: Modeling general, shared, and person specific processes in personality and psychopathology. Psychological Assessment, 31, 502-515. https:// doi.org/10.1037/pas0000617

Wright, A. G., Pincus, A., \& Hopwood, C. J. (2020). Contemporary integrative interpersonal theory: integrating structure. Dynamics, Temporal Scale, and Levels of Analysis. Advance Online Publication. https://doi.org/10.31234/osf.io/fknc8

Wright, A. G. C., Stepp, S. D., Scott, L. N., Hallquist, M. N., Beeney, J. E., Lazarus, S. A., \& Pilkonis, P. A. (2017). The effect of pathological narcissism on interpersonal and affective processes in social interactions. Journal of Abnormal Psychology, 126, 898-910. https://doi.org/10.1037/ab n0000286 
Wright, A. G. C., \& Zimmermann, J. (2019). Applied ambulatory assessment: Integrating idiographic and nomothetic principles of measurement. Psychological Assessment, 31, 1467-1480. https:// doi.org/10.1037/pas0000685

Wrzus, C. (2020). Processes of personality development: An update of the TESSERA framework. In J. Rauthmann (Ed.), The handbook of personality dynamics and processes. Amsterdam, The Netherlands: Elsevier.

Wrzus, C., \& Mehl, M. R. (2015). Lab and/or Field? Measuring personality processes and their social consequences. European Journal of Personality, 29, 250-271. https://doi.org/10.1002/per. 1986

Wrzus, C., \& Roberts, B. W. (2017). Processes of personality development in adulthood: The TESSERA framework. Personality and Social Psychology Review, 21, 253-277. https://doi.org/ $10.1177 / 1088868316652279$

Zhang, J., Beckmann, N., \& Beckmann, J. F. (2019). One situation doesn't fit all: Variability and stability of state willingness to communicate in a Chinese College English classroom. Language Teaching Research. Advance Online Publication. https://doi.org/10.1177/1362168819891330

Zimmermann, J., Woods, W. C., Ritter, S., Happel, M., Masuhr, O., Jaeger, U., .. Wright, A. G. C. (2019). Integrating structure and dynamics in personality assessment: First steps toward the development and validation of a personality dynamics diary. Psychological Assessment, 31(4), 516-531. https://doi.org/10.1037/pas0000625

Received 28 July 2020; revised version received 3 December 2020 